Technical Paper

\title{
Factors on Palm Oil Fruit Bunches Production Volume for Biomass Fuel and Biofuel During Cogeneration Processes
}

\author{
Noraini ABDUllaH, Chen Lee LEE and Zainodin Haji JuBoK
}

(Received March 16, 2015)

\begin{abstract}
Studies on palm oil cogeneration systems, and design and analysis to further improve the energy efficiency have been done based on process integration technology. The products during cogeneration are crude palm oil (CPO) and solid wastes which come from empty fruit bunches, fibers and nutshells. However, factors affecting the production of biomass and biofuel from solid wastes and crude palm oil from oil palm fruit bunches for the boilerbased and combustion-based cogeneration can be further explored. This study hence aims to determine these factors, and then expound further in forecasting the production volume of biomass fuel and biofuel produced during cogeneration. For this purpose, the multiple regression (MR) technique is employed, and the results based on the mathematical modelling concept are thus compared. Mathematical models on the production of oil palm fruit bunches are developed via the model-building processes. Data variables are transformed using the ladderpower transformation method from a data set of 31 observations. Two models are developed, namely, Model I is for the production volume on biomass fuel from fresh oil palm fruit bunches, while Model II is the production volume on liquid biofuel from crude palm oil (CPO). There are five independent variables in Model I, and four independent variables in Model II. The four-phase in multiple regression model-building are carried out to change the nonnormal data to normality. The best model obtained by the model transformation method in Model I is M72.2.5 where the main factor is the total workers employed during last pay period, and interaction factors up to the second order are: harvested area interact with yield per hectare, harvested area interact with local delivery average price, harvested area interact with total workers employed during last pay period, yield per hectare interact with local delivery average price, harvested area interact with local delivery average price interact with total workers employed during last pay period and yield per hectare interact with local delivery average price interact with total workers employed during last pay period. The significant factors on the biomass production are the yield per hectare and the harvested area of the oil palm fruit bunches. The mean absolute prediction error (MAPE) value for the best model on model transformation Model II is $2.62 \%$. Thus, the best model using the model transformation method is said to be excellent and acceptable to forecast for the production volume of biomass fuel and biofuel during cogeneration.
\end{abstract}

\section{Key Words}

Multiple regression (MR), Ladder-power transformation, Production volume, Biomass fuel, Biofuel

\section{Introduction}

One of the most important Malaysia's leading export commodities is crude palm oil (CPO), and it has been contributing to the Malaysia' s economy income since the nineteenth century. Besides $\mathrm{CPO}$ being used to produce liquid biofuel eg. biodiesel which is biodegradable and a

Mathematics with Economics Programme, Faculty of Science and Natural Resources of Universiti Malaysia Sabah

Kota Kinabalu, Sabah, 88400, Malaysia non-toxic fuel, biomass which is the solid wastes including empty fruit bunches, fibers, nutshells and agro-wastes from harvest, can be used as biomass fuel in the boilerbased cogeneration system ${ }^{1)}$ as shown in Fig. 1. Ultimately, it has the potential to increase the global demand for this sustainable commodity by creating a new market for biomass energy from agro wastes, and liquid biofuel from CPO. Biofuel production is the process of producing the liquid biofuel such as biodiesel, through the chemical 


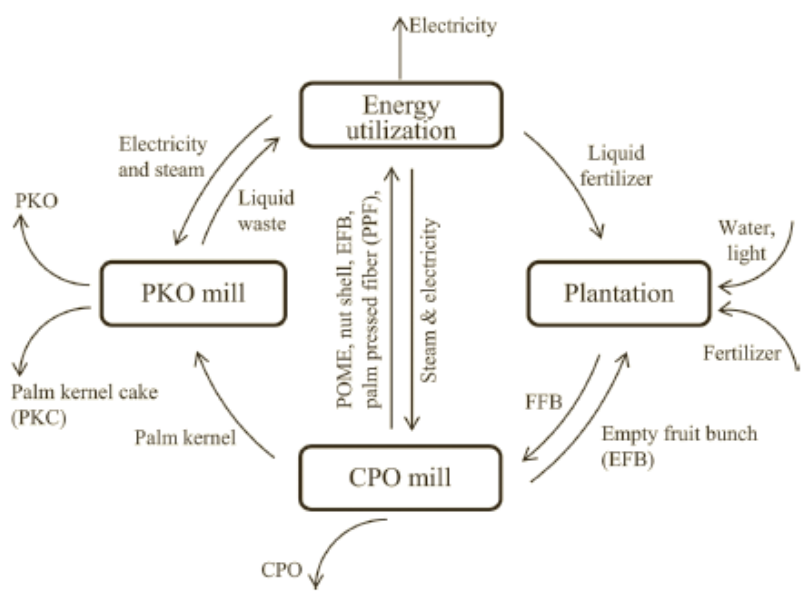

Fig. 1 Basic Material and Energy Flows during Cogeneration Processes

reactions of transesterification and esterification, while biomass fuel is the byproduct fuel from its solid wastes. Hence, biomass fuel and liquid biofuel such as biodiesel have become more attractive recently because of its environmental benefits, and moreover by the fact that it is made from renewable resources.

In the beginning of 2004, the increases in the petroleum prices have provided the motivational force for turning to biomass fuel and biofuel as energy and transportation fuel ${ }^{2)}$. It converts the cheapest palm oil, rapeseed oil or soybean oil into biodiesel. These oils are sold at the price of petroleum diesel so as to earn a gross profit margin, besides in addition obtaining biomass fuel from solid wastes and biofuel, for example from $\mathrm{CPO}$ during the cointegration processes.

The oil palm plantation and its production of fruit bunches in the international market has been increasing from time to time. In this study, it is intended to find the optimal production of biomass from fruit bunches for biomass fuel, and then do forecasting of liquid biofuel from $\mathrm{CPO}$. At present, there are many factors that can influence the production of fresh oil palm fruit bunches from the oil palm plantations. This research will identify the significant factors on the relationship of the production of the oil palm fruit bunches with the planted area, harvested area, yield per hectare of oil palm fruit bunches, local delivery average price, and the total number of workers employed during the last pay period in an oil palm plantation. An increase in the planted area is expected to increase the production of oil palm fruits. Even though the expansion of the palm oil plantation helps to increase the total production of palm oil fruit bunches, it does not reflect the technological and scientific advances made ${ }^{3)}$. However, it can help in predicting the potential volume of biomass fuel (and liquid biofuel) produced during the cointegration processes, and thus contributes in the cost and benefit analysis.

Production of oil palm fruits bunches from countries like Malaysia and Indonesia will keep increasing in the future due to the increase in the planted areas that have entered the maturity stage. Oil palm fruits when reaching their maturity stage would depend on many factors arising from technological problems, geology problems and also environmental problems. Yield of oil palm fruits is normally assumed to depend on the technological advancement of its production. Besides that, the discovery of new high yielding varieties, improvements in planting techniques and the increasing use of fertilizers and chemicals will hence increase the yield. Supposedly when the oil palm production increases, the palm oil price will also be reduced. The price of palm oil started to reduce in 2005 due to an increase in its production and a reduction in the price of its substitute goods; namely soya bean oil. Hence, there is a negative relationship between the price of palm oil and its production in Malaysia ${ }^{3)}$. Increase in the production of oil palm will cause the total number of workers employed to be increased. Therefore, the total number of workers employed is also one of the factors that can influence the production of oil palm. If there is a lack of workers in the industry, not just the process of harvesting and processing the fruits, even the process of extracting and generating the oil will also become inefficient.

In this study, multiple regressions (MR) is used which is a statistical technique relating the significant factors affecting the production volume on biomass fuel from empty oil palm fruit bunches. The best multiple regression model developed can further be used for forecasting the production volume on liquid biofuel from the crude palm oil (CPO) produced, based on the Mean Absolute Percentage Error (MAPE).

The purpose of this study is to determine the factors affecting the production of biomass and biofuel, and then expound further in forecasting the production volume of biomass fuel and biofuel produced during cogeneration.

\section{Materials and methods}

Data Collection: This research was conducted based on the production volume of fresh oil palm fruit bunches from plantations in Malaysia. A total of 31 data sets on oil palm from 1982 till 2011 were collected ${ }^{4}$, and obtained through the internet official website ${ }^{5}$. From these 31 data sets, 26 data sets will be used for modelling, while five have been selected randomly and reserved for forecasting. Two models obtained, namely Model I (from modelling) and Model II (for forecasting) respectively are developed involving these two different sets of data variables. Model 


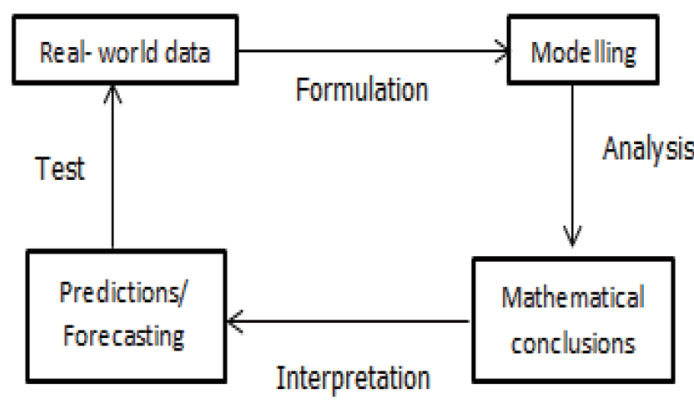

Fig. 2 Basic process in Mathematical modeling

I comprises of the 26 data sets from oil palm plantations which include the solid biomass production from fresh oil palm fruit bunches (P1) in t, planted area (A) in ha, harvested area $(H)$ in ha, yield per hectare $(Y d)$ in $t / h a$, local delivery average price (Ap) in USD/t and total workers in thousands persons ('000), employed during the last pay period (Tw) (viz. the day you get your exact amount pay). From Model I, the production volume model is obtained via the modelling processes carried out using the normality test, data transformation and model-building phases, while forecasting is executed for verification of model's robustness and efficiency in Model II. Model II comprises of the five data sets on the production volume of liquid biofuel (PVol) in $\mathrm{L} / \mathrm{t}$, production volume of biomass from oil palm fruit bunches in Model I (P1) in t/year, export value of liquid biofuel (biodiesel) (EVal) in USD/L, gross domestic product (GDP) in USD/person year, and gross national income (GNI) in USD/year. A flowchart on the basic processes in mathematical modeling is shown in Fig. ${ }^{6)}$.

\subsection{Normality Test}

In statistics, normality tests are used to determine if a data set is well-modeled by a normal distribution, and to compute how likely it is for a random variable underlying the data set to be normally distributed visually supported by the frequency distribution (or histogram) and the Q-Q plot (quantile-quantile plot). Both the histogram and Q-Q plots were supporting evidences, while the numerical statistical tests used, depending on the number of observations (n) were the Kolmogorov-Smirnov (for $n>50$ ) and ShapiroWilk (for $\mathrm{n}$ <50). If the significance level is larger than 0.05 , then the alternative hypothesis is rejected and therefore normality is assumed. On the other hand, if the significance level is less than 0.05 , then the null hypothesis is rejected and thus normality is not assumed.

\subsection{Model Transformation}

In this research, model transformation method will be used in Model I to change the non-normality data
Table 1 Commonly used transformations

\begin{tabular}{c|c|c}
\hline Ladder-Power & Transformed Value & Name \\
\hline 3 & Original value) $^{3}$ & Cube \\
\hline 2 & Original value $^{2}$ & Square \\
\hline 1 & Original value & No transformation \\
\hline $1 / 2$ & Original value) $^{1 / 2}$ & Square root \\
\hline $1 / 3$ & $($ Original value) & Cube root \\
\hline 0 & log(Original value) & Logarithm \\
\hline$-1 / 2$ & Original value) $^{1 / 2}$ & Reciprocal root \\
\hline-1 & (Original value) $^{-1}$ & Reciprocal \\
\hline-2 & (Original value) $^{-2}$ & Reciprocal square \\
\hline
\end{tabular}

into normality for the production model on fresh oil palm fruit bunches. Data transformation is needed on the nonnormal data so as to more closely approximate a theoretical distribution with statistical properties. Transforming the data can spread the data more evenly and hence, make the distributions more symmetrical. Besides, the relationships between variables are more linear and the data have constant variance. Table 1 displays a "ladder" of the most commonly used power transformations used as in this research.

A power transformation is a type of transformation that statisticians have found useful for straightening a plot ${ }^{7}$. A power is first selected, and each original value is raised to that power to obtain the corresponding transformed value. The power of 1 corresponds to no transformation, while the power of 0 will transform every value to 1 , which is certainly not informative. Therefore, statisticians use the logarithmic transformation in its place in the ladder of transformations.

\section{Multiple regression model-building}

Hierarchical multiple regression technique is used to relate a dependent variable $\mathrm{Y}$, to several independent variables $\mathrm{W}_{1}, \mathrm{~W}_{2}, \cdots$, Wk. Multiple Regressions (MR) models are used by forming several regression equations and different statistical tests are run through the EXCEL and SPSS programs in order to determine these relationships. The general regression model equation can be written in the form as in equation (1) ${ }^{8)}$ :

$$
\mathrm{Y}=\Omega_{0}+\Omega_{1} \mathrm{~W}_{1}+\Omega_{2} \mathrm{~W}_{2}+\ldots+\Omega_{\mathrm{k}-1} \mathrm{~W}_{\mathrm{k}-1}+\Omega_{\mathrm{k}} \mathrm{W}_{\mathrm{k}}+\mathrm{u}
$$

with $\Omega_{0}$ denotes as the constant term, $\Omega_{\mathrm{j}}$ is the $\mathrm{j}$-th coefficient of the independent variable, $W_{j}$ for $j=1,2, \cdots, k$ where ' $\mathrm{k}$ ' is the number of independent variables, and ' $\mathrm{u}$ ' denotes the residuals of the regression model equation. In this research, the independent variables would take the form of transformed variables using ladder transformation of non-normal variables to normality. All possible equations for Model I are depicted in the Appendix. Basic assumptions of the multiple regression models can be referred to as in Zainodin et al. ${ }^{8)}$. 


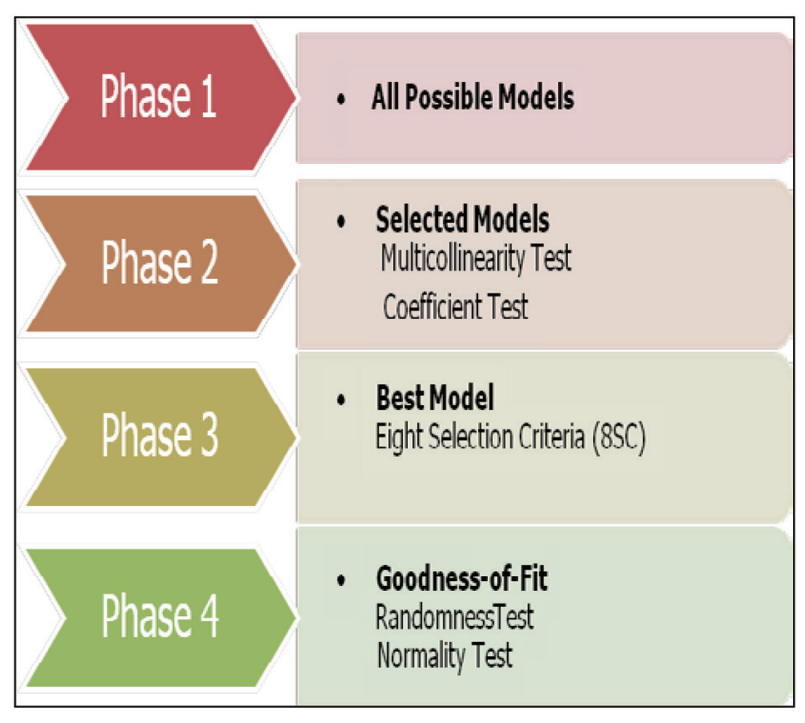

Fig. 3 Multiple regression model-building summaries

The four phase multiple regression (MR) modelbuilding summaries carried out in this research are shown as in Fig. $3^{8)}$.

The total number of possible models of Phase 1 is calculated as shown by the formula ${ }^{9) \sim 11)}$.

$$
N=\sum_{i=1}^{q} j\left({ }^{q} C_{j}\right)
$$

In equation (2), $\mathrm{N}$ is the number of all possible models, and ' $q$ ' is the number of single quantitative independent variables. For example, with five single independent variables, the number of all possible models $\mathrm{N}$ is calculated as:-

$$
\begin{aligned}
N & =1 \cdot{ }^{5} C_{1}+2 \cdot{ }^{5} C_{2}+3 \cdot{ }^{5} C_{3}+4 \cdot{ }^{5} C_{4}+5 \cdot{ }^{\cdot 5} C_{5} \\
& =5+20+30+20+5 \\
& =80
\end{aligned}
$$

The interactions of the single independent variables $\left(\mathrm{X}_{1} \mathrm{X}_{2}\right.$ - first order interaction between $\mathrm{X}_{1}$ and $\mathrm{X}_{2} ; \mathrm{X}_{1} \mathrm{X}_{2} \mathrm{X}_{3}$ second order interaction between $\mathrm{X}_{1}, \mathrm{X}_{2}$ and $\mathrm{X}_{3}, \mathrm{X}_{1} \mathrm{X}_{2} \mathrm{X}_{3} \mathrm{X}_{4}$ third order interaction between $\mathrm{X}_{1}, \mathrm{X}_{2}, \mathrm{X}_{3}$ and $\mathrm{X}_{4} ; \mathrm{X}_{1} \mathrm{X}_{2} \mathrm{X}_{3} \mathrm{X}_{4}$ $\mathrm{X}_{5}$ - fourth order interaction between $\mathrm{X}_{1}, \mathrm{X}_{2}, \mathrm{X}_{3}, \mathrm{X}_{4}$ and $\mathrm{X}_{5}$ ) denote the product of these variables, and can be rewritten as $\mathrm{X}_{12}, \mathrm{X}_{123}$ and $\mathrm{X}_{1234}$ respectively ${ }^{8}$. All the possible models would undergo through the Global test as shown by Zainodin and Khuneswari ${ }^{12}$. The selected models of Phase 2 will then undergo two tests, namely, the correlation based multicollinearity test ${ }^{13)}$ and the coefficient test ${ }^{14)}$ at $\alpha=5 \%$ significant level. Each variable removal due to multicollinearity, and backward elimination of insignificant variables from the model using the coefficient test would be denoted in the model labelling ${ }^{15)}$ as shown in Fig. 4 whereby the parent model is denoted by (Ma). In Phase 2 of model-building as shown in Fig. 3, the multicollinearity and coefficient tests are carried out on all the possible models.

\begin{tabular}{|c|c|}
\hline \multicolumn{2}{|c|}{ EIGHT SELECTION CRITERIA (8SC) } \\
\hline $\begin{array}{l}\text { AIC: (Akaike, 1974) }{ }^{16)} \\
\left(\frac{S S E}{n}\right)(e)^{2(k+1) / n}\end{array}$ & $\begin{array}{l}\text { RICE: (Rice, 1984) 17) } \\
\left(\frac{S S E}{N}\right)\left[1-\left(\frac{2(\mathrm{k}+1)}{n}\right)\right]^{-1}\end{array}$ \\
\hline $\begin{array}{l}\text { FPE: (Akaike, 1969) }{ }^{18)} \\
\left(\frac{S S E}{N}\right) \frac{n+(k+1)}{n-(k+1)}\end{array}$ & $\begin{array}{l}\text { SCHWARZ: (Schwarz, 1978) }{ }^{19)} \\
\qquad\left(\frac{S S E}{n}\right) n^{(k+1) / n}\end{array}$ \\
\hline $\begin{array}{l}\text { GCV: (Golub et al., 1979) } 20) \\
\left(\frac{S S E}{N}\right)\left[1-\left(\frac{k+1}{n}\right)\right]^{-2}\end{array}$ & $\begin{array}{l}\text { SGMASQ: (Ramanathan, 2002) } \\
\left(\frac{S S E}{n}\right)\left[1-\left(\frac{\mathrm{k}+1}{n}\right)\right]^{-1}\end{array}$ \\
\hline $\begin{array}{l}\text { HQ: (Hannan \& Quinn, 1979) } 22) \\
\qquad\left(\frac{S S E}{n}\right)(\ln n)^{2(k+1) / n}\end{array}$ & $\begin{array}{l}\text { SHIBATA: (Shibata, 1981) } \\
\qquad\left(\frac{S S E}{n}\right) \frac{n+2(k+1)}{n}\end{array}$ \\
\hline
\end{tabular}

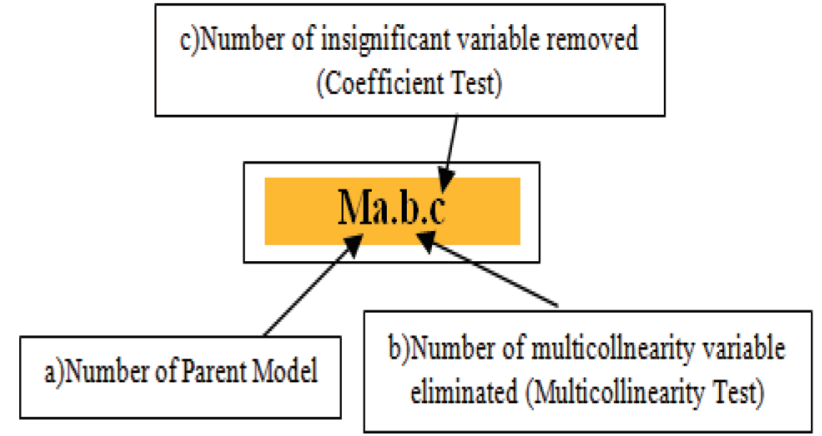

Fig. 4 Model labelling in multiple regression

Table 2 Eight selection criteria (8SC) model selection

The number of variables eliminated due to multicollinearity test is denoted by the label (.b), while the number of variables removed by the coefficient test is denoted by the label (.c). Further illustrations on model labelling can be found in Zainodin et al. ${ }^{15)}$.

The best model of Phase 3 will be chosen from the selected models, with the minimum values based on the eight selection criteria (8SC) in Table 2, as shown by Noraini et al. ${ }^{9)}$ and Noraini and Zainodin ${ }^{11}$. The eight selection criteria are: Akaike Information Criterion (AIC), Final Prediction Error (FPE), GCV (Generalized Cross Validation, HQ (Hannan and Quinn) Criterion, RICE, SCHWARZ, SGMASQ and SHIBATA, where $\mathrm{n}$ is the number of observations, $\mathrm{k}$ is the number of independent variables, $(\mathrm{k}+1)$ is the number of parameters, and SSE is the sum of square error of each model.

The best model will then undergo through the goodness-of-fit tests in Phase 4, namely, the randomness test using the scatter plot, and the normality test on the standardized residuals. These multiple regression modelbuilding are performed on all the models in this research.

The Mean Absolute Percentage Error (MAPE) is commonly used in quantitative forecasting methods as it produces a measure of the relative overall fit as a ratio or 
in percentage. The absolute values of all the percentage errors are summed up and the average is calculated, and is computed as the difference between the actual value (At) and forecasted value (Ft) and is divided by the actual value (At) again. The lower the MAPE value is, the best the model can be. It can then be used in forecasting or evaluating the missing values. The MAPE of the best model is thus calculated so that its efficiency in forecasting the future production volume of biofuel can therefore be made. The acceptable range for the MAPE test is less than $25 \%{ }^{20)}$, where the smaller value of MAPE would give a better prediction. The MAPE formula is given by ${ }^{12)}$ :

$$
\text { MAPE }=\frac{1}{m} \sum_{t=1}^{m}\left|\frac{A t-F t}{A t}\right|
$$

The MAPE formula in (3) is given by actual value At, the forecasted value Ft, and number of randomly selected data reserved for verification of the model, ' $m$ '.

\section{Results and findings}

Using equation (2), Table 3 shows the number of all possible models of Model I for the production volume (80 models) with its corresponding number of variables. The production model on the fresh oil palm fruit bunches contains one dependent variable (P1) and five independent variables (A, H, Yd, Ap and Tw).

Table 4 shows the normality tests for Model I (Shapiro-Wilk: $\mathrm{df}=26$ ) on the variables before and after transformation using the ladder-power transformation method. It can be seen that all the non-normal variables (Yd, Ap and Tw) with $\mathrm{p}$ values $<0.05$ have turned to normal after the appropriate transformation with all their $\mathrm{p}$ values

Table 3 All possible models with five independent variables (Model I)

\begin{tabular}{|c|c|c|c|c|c|c|}
\hline \multirow{2}{*}{$\begin{array}{c}\text { Number of } \\
\text { variables }\end{array}$} & \multirow[t]{2}{*}{ Single } & \multicolumn{4}{|c|}{ Order of Interactions } & \multirow[t]{2}{*}{ Total } \\
\hline & & 1st & 2nd & $3 \mathrm{rd}$ & 4 th & \\
\hline 1 & 5 & - & - & - & - & 5 \\
\hline 2 & 10 & 10 & - & - & - & 20 \\
\hline 3 & 10 & 10 & 10 & - & - & 30 \\
\hline 4 & 5 & 5 & 5 & 5 & - & 20 \\
\hline 5 & 1 & 1 & 1 & 1 & 1 & 5 \\
\hline Total & 31 & 26 & 16 & 6 & 1 & 80 \\
\hline
\end{tabular}

$>0.05$ (Table 4). This is further supported by the normality plots as depicted in Fig. 5.

Similarly, using equation (2), Table 5 shows the number of all possible models for Model II (i.e. 32 models) with its corresponding number of variables.

Table 5 shows the number of possible models for Model II which contains one dependent variable (PVol) and four independent variables (P1, EVal, GDP and GNI). Table 6 shows the normality tests (Shapiro-Wilk: $\mathrm{df}=5$ ) on these variables. Thus, no transformation is needed on the variables for Model II.

Phase 2 in MR model-building is then carried out on the possible models of the transformed variables. The multicollinearity test is carried out on all the models as illustrated by Noraini and Zainodin ${ }^{13)}$, and followed by the coefficient test using backward elimination, as shown by Noraini et al. ${ }^{14)}$. This has resulted in 34 selected models being obtained for Model I. Phase 3 is then carried to

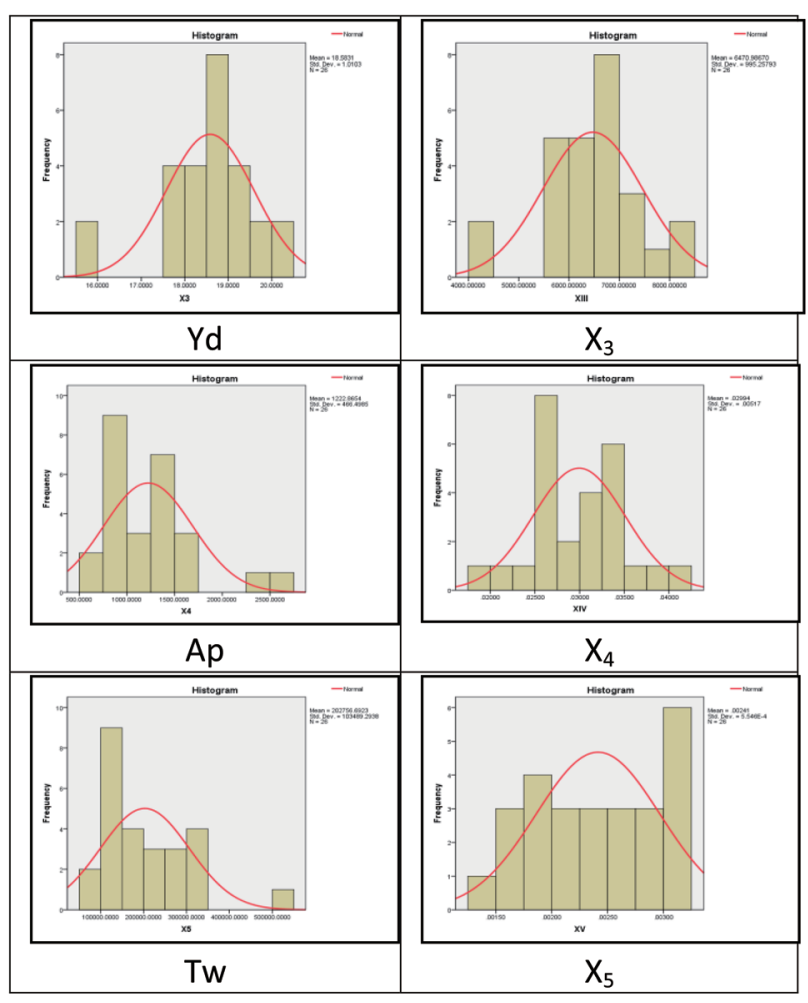

Fig. 5 Normality plots before and after transformations (Model I)

Table 4 Normality teste before and after transformation (Model I)

\begin{tabular}{c|c|c|c|c|c|c}
\hline & \multicolumn{3}{|c|}{ Before Transformation } & \multicolumn{3}{c}{ After Transformation } \\
\hline Model 1 & Statistics & P-value & & & Statistics & P-value \\
\hline P1 & 0.948 & 0.210 & Normal & Y=P1 & 0.210 & 0.210 \\
\hline A & 0.936 & 0.105 & Normal & $\mathrm{X}_{1}=\mathrm{A}$ & 0.105 & 0.105 \\
\hline H & 0.941 & 0.145 & Normal & $\mathrm{X}_{2}=\mathrm{H}$ & 0.145 & 0.145 \\
\hline Yd & 0.898 & 0.014 & Not normal & $\mathrm{X}_{3}=(\mathrm{Yd})^{3}$ & 0.934 & 0.094 \\
\hline $\mathrm{Ap}$ & 0.878 & 0.005 & Not normal & $\mathrm{X}_{4}=(\mathrm{Ap})^{-1 / 2}$ & 0.974 & 0.716 \\
\hline $\mathrm{Tw}$ & 0.879 & 0.005 & Not normal & $\mathrm{X}_{5}=(\mathrm{Tw})^{-1 / 2}$ & 0.943 & 0.155 \\
\hline
\end{tabular}


Table 5 All possible models with four independent variables (Model II)

\begin{tabular}{c|c|c|c|c|c}
\hline $\begin{array}{c}\text { Number of } \\
\text { variables }\end{array}$ & Single & \multicolumn{3}{|c|}{ Order of Interactions } & Total \\
\hline & & 1st & 2nd & 3rd & \\
\hline 1 & 4 & - & - & - & 4 \\
\hline 2 & 6 & 6 & - & - & 12 \\
\hline 3 & 4 & 4 & 4 & - & 12 \\
\hline 4 & 1 & 1 & 1 & 1 & 4 \\
\hline Total & 15 & 11 & 5 & 1 & 32 \\
\hline
\end{tabular}

Table 6 Normality tests (Model II)

\begin{tabular}{l|l|c|c|c}
\hline \multirow{2}{*}{ Model II } & \multirow{2}{*}{ Units } & \multicolumn{3}{c}{ Shapiro-Wilk (Df=5) } \\
\cline { 3 - 5 } & & Statistic & P-value & Normality \\
\hline $\mathrm{PVol}$ & Litres/year (L/yr) & 0.917 & 0.509 & Normal \\
\hline $\mathrm{Pl}=>\mathrm{X}_{1}$ & Tonnes/year (t/yr) & 0.964 & 0.839 & Normal \\
\hline Eval $=>\mathrm{X}_{2}$ & USD/ton (USD/t) & 0.797 & 0.077 & Normal \\
\hline $\mathrm{GDP}=>\mathrm{X}_{3}$ & USD/person/year & 0.985 & 0.959 & Normal \\
\hline $\mathrm{GNI}=>\mathrm{X}_{4}$ & USD/year & 0.980 & 0.936 & Normal \\
\hline
\end{tabular}

choose the best model based on the eight selection criteria (8SC). Table 7 shows some selected models with their 8SC values. It can be seen that the best model which has the minimum values of all the eight selection criteria (8SC) is given by model M72.2.5 with two multicollinearity source variables being removed, and five insignificant variables being eliminated. Model M72.2.5 would then undergo finally Phase 4 of the goodness-of-fit tests for model validation to be used for forecasting.

Model M72 is given as in (1) by equation (3) below:

$$
\begin{aligned}
\text { M72.0.0: } & Y=\beta_{0}+\beta_{2} X_{2}+\beta_{3} X_{3}+\beta_{4} X_{4}+\beta_{5} X_{5}+\beta_{23} X_{23} \\
& +\beta_{24} X_{24}+\beta_{25} X_{25}+\beta_{34} X_{34}+\beta_{35} X_{35}+\beta_{34} X_{34}+ \\
& \beta_{45} X_{45}+\beta_{234} X_{234}+\beta_{235} X_{235}+\beta_{245} X_{245}+\beta_{345} X_{345} \\
& +\mathrm{u}
\end{aligned}
$$

\begin{tabular}{|c|c|c|c|c|c|c|c|c|}
\hline $\begin{array}{c}\text { Selected } \\
\text { model }\end{array}$ & AIC & FPE & GCV & $\mathrm{HQ}$ & RICE & SCHWARZ & SGMASQ & SHIBATA \\
\hline M1.0.0 & $5.366 \times 10^{12}$ & $5.367 \times 10^{12}$ & $5.399 \times 10^{12}$ & $5.517 \times 10^{12}$ & $5.437 \times 10^{12}$ & $5.911 \times 10^{12}$ & $4.984 \times 10^{12}$ & $5.308 \times 10^{12}$ \\
\hline M2.0.0 & $3.495 \times 10^{12}$ & $3.496 \times 10^{12}$ & $3.517 \times 10^{12}$ & $3.594 \times 10^{12}$ & $3.542 \times 10^{12}$ & $3.851 \times 10^{12}$ & $3.247 \times 10^{12}$ & $3.458 \times 10^{12}$ \\
\hline M4.0.0 & $2.141 \times 10^{14}$ & $2.142 \times 10^{14}$ & $2.155 \times 10^{14}$ & $2.202 \times 10^{14}$ & $2.170 \times 10^{14}$ & $2.359 \times 10^{14}$ & $1.989 \times 10^{14}$ & $2.118 \times 10^{14}$ \\
\hline M5.0.0 & $1.321 \times 10^{13}$ & $1.321 \times 10^{13}$ & $1.329 \times 10^{13}$ & $1.358 \times 10^{13}$ & $1.338 \times 10^{13}$ & $1.455 \times 10^{13}$ & $1.227 \times 10^{13}$ & $1.307 \times 10^{13}$ \\
\hline M7.0.0 & $1.979 \times 10^{12}$ & $1.981 \times 10^{12}$ & $2.008 \times 10^{12}$ & $2.063 \times 10^{12}$ & $2.042 \times 10^{12}$ & $2.288 \times 10^{12}$ & $1.776 \times 10^{12}$ & $1.934 \times 10^{12}$ \\
\hline M10.0.0 & $9.560 \times 10^{11}$ & $9.570 \times 10^{11}$ & $9.699 \times 10^{11}$ & $9.969 \times 10^{11}$ & $9.867 \times 10^{11}$ & $1.105 \times 10^{11}$ & $8.580 \times 10^{11}$ & $9.342 \times 10^{11}$ \\
\hline M13.0.0 & $1.901 \times 10^{14}$ & $1.903 \times 10^{14}$ & $1.928 \times 10^{14}$ & $1.982 \times 10^{14}$ & $1.962 \times 10^{14}$ & $2.198 \times 10^{14}$ & $1.706 \times 10^{14}$ & $1.857 \times 10^{14}$ \\
\hline M14.0.0 & $1.174 \times 10^{13}$ & $1.176 \times 10^{13}$ & $1.191 \times 10^{13}$ & $1.225 \times 10^{13}$ & $1.212 \times 10^{13}$ & $1.358 \times 10^{13}$ & $1.054 \times 10^{13}$ & $1.148 \times 10^{13}$ \\
\hline M15.0.0 & $1.110 \times 10^{13}$ & $1.111 \times 10^{13}$ & $1.126 \times 10^{13}$ & $1.157 \times 10^{13}$ & $1.146 \times 10^{13}$ & $1.283 \times 10^{13}$ & $9.962 \times 10^{13}$ & $1.085 \times 10^{13}$ \\
\hline M39.1.0 & $1.791 \times 10^{14}$ & $1.793 \times 10^{14}$ & $1.817 \times 10^{14}$ & $1.867 \times 10^{14}$ & $1.848 \times 10^{14}$ & $2.070 \times 10^{14}$ & $1.607 \times 10^{14}$ & $1.750 \times 10^{14}$ \\
\hline M40.0.1 & $1.112 \times 10^{13}$ & $1.113 \times 10^{13}$ & $1.128 \times 10^{13}$ & $1.160 \times 10^{13}$ & $1.148 \times 10^{13}$ & $1.286 \times 10^{13}$ & $9.983 \times 10^{13}$ & $1.087 \times 10^{13}$ \\
\hline M42.3.0 & $2.540 \times 10^{12}$ & $2.546 \times 10^{12}$ & $2.608 \times 10^{12}$ & $2.685 \times 10^{12}$ & $2.697 \times 10^{12}$ & $3.082 \times 10^{12}$ & $2.206 \times 10^{12}$ & $2.441 \times 10^{12}$ \\
\hline M45.1.1 & $1.087 \times 10^{12}$ & $1.093 \times 10^{12}$ & $1.134 \times 10^{12}$ & $1.166 \times 10^{12}$ & $1.203 \times 10^{12}$ & $1.385 \times 10^{12}$ & $9.163 \times 10^{12}$ & $1.025 \times 10^{12}$ \\
\hline M46.1.1 & $6.782 \times 10^{11}$ & $6.815 \times 10^{11}$ & $7.077 \times 10^{11}$ & $7.271 \times 10^{11}$ & $7.502 \times 10^{11}$ & $8.638 \times 10^{11}$ & $5.716 \times 10^{11}$ & $6.392 \times 10^{11}$ \\
\hline M48.1.1 & $4.142 \times 10^{11}$ & $4.163 \times 10^{11}$ & $4.322 \times 10^{11}$ & $4.441 \times 10^{11}$ & $4.582 \times 10^{11}$ & $5.276 \times 10^{11}$ & $3.491 \times 10^{11}$ & $3.904 \times 10^{11}$ \\
\hline M49.1.1 & $1.494 \times 10^{11}$ & $1.502 \times 10^{11}$ & $1.559 \times 10^{11}$ & $1.602 \times 10^{11}$ & $1.653 \times 10^{11}$ & $1.904 \times 10^{11}$ & $1.260 \times 10^{11}$ & $1.409 \times 10^{11}$ \\
\hline M51.0.1 & $9.304 \times 10^{12}$ & $9.349 \times 10^{12}$ & $9.708 \times 10^{12}$ & $9.976 \times 10^{12}$ & $1.029 \times 1013$ & $1.185 \times 10^{12}$ & $7.841 \times 10^{12}$ & $8.769 \times 10^{12}$ \\
\hline M52.4.2 & $1.293 \times 10^{12}$ & $1.299 \times 10^{12}$ & $1.349 \times 10^{12}$ & $1.386 \times 10^{12}$ & $1.430 \times 10^{12}$ & $1.647 \times 10^{12}$ & $1.090 \times 10^{12}$ & $1.219 \times 10^{12}$ \\
\hline M53.5.1 & $6.782 \times 10^{11}$ & $6.815 \times 10^{11}$ & $7.077 \times 10^{11}$ & $7.271 \times 10^{11}$ & $7.502 \times 10^{11}$ & $8.638 \times 10^{11}$ & $5.716 \times 10^{11}$ & $6.392 \times 10^{11}$ \\
\hline M54.6.2 & $1.299 \times 10^{13}$ & $1.301 \times 10^{13}$ & $1.318 \times 10^{13}$ & $1.355 \times 10^{13}$ & $1.341 \times 10^{13}$ & $1.502 \times 10^{13}$ & $1.166 \times 10^{13}$ & $1.270 \times 10^{13}$ \\
\hline M55.1.1 & $4.933 \times 10^{11}$ & $5.083 \times 10^{11}$ & $5.775 \times 10^{11}$ & $5.592 \times 10^{11}$ & $8.023 \times 10^{11}$ & $7.626 \times 10^{11}$ & $3.776 \times 10^{11}$ & $4.178 \times 10^{11}$ \\
\hline M56.1.2 & $3.617 \times 10^{10}$ & $3.692 \times 10^{10}$ & $4.078 \times 10^{10}$ & $4.043 \times 10^{10}$ & $5.082 \times 10^{10}$ & $5.327 \times 10^{10}$ & $2.823 \times 10^{10}$ & $3.158 \times 10^{10}$ \\
\hline M57.6.3 & $3.425 \times 10^{11}$ & $3.472 \times 10^{11}$ & $3.744 \times 10^{11}$ & $3.776 \times 10^{11}$ & $4.332 \times 10^{11}$ & $4.806 \times 10^{11}$ & $2.736 \times 10^{11}$ & $3.076 \times 10^{11}$ \\
\hline M65.1.0 & $7.992 \times 10^{10}$ & $8.101 \times 10^{10}$ & $8.734 \times 10^{10}$ & $8.810 \times 10^{10}$ & $1.011 \times 10^{10}$ & $1.121 \times 10^{10}$ & $6.383 \times 10^{10}$ & $7.176 \times 10^{10}$ \\
\hline M66.1.3 & $3.253 \times 10^{12}$ & $3.261 \times 10^{12}$ & $3.340 \times 10^{12}$ & $3.439 \times 10^{12}$ & $3.454 \times 10^{12}$ & $3.947 \times 10^{12}$ & $2.826 \times 10^{12}$ & $3.127 \times 10^{12}$ \\
\hline M67.0.4 & $8.890 \times 10^{12}$ & $8.912 \times 10^{12}$ & $9.128 \times 10^{12}$ & $9.399 \times 10^{12}$ & $9.440 \times 10^{12}$ & $1.079 \times 10^{12}$ & $7.723 \times 10^{12}$ & $8.546 \times 10^{12}$ \\
\hline M68.8.2 & $1.293 \times 10^{12}$ & $1.299 \times 10^{12}$ & $1.349 \times 10^{12}$ & $1.386 \times 10^{12}$ & $1.430 \times 10^{12}$ & $1.647 \times 10^{12}$ & $1.090 \times 10^{12}$ & $1.219 \times 10^{12}$ \\
\hline M69.8.2 & $6.529 \times 10^{11}$ & $6.561 \times 10^{11}$ & $6.813 \times 10^{11}$ & $7.000 \times 10^{11}$ & $7.222 \times 10^{11}$ & $8.316 \times 10^{11}$ & $5.503 \times 10^{11}$ & $6.154 \times 10^{11}$ \\
\hline M71.2.5 & $4.738 \times 10^{11}$ & $4.837 \times 10^{11}$ & $5.342 \times 10^{11}$ & $5.297 \times 10^{11}$ & $6.658 \times 10^{11}$ & $6.978 \times 10^{11}$ & $3.699 \times 10^{11}$ & $4.136 \times 10^{11}$ \\
\hline M72.2.5 & $1.418 \times 10^{10}$ & $1.447 \times 10^{10}$ & $1.599 \times 10^{10}$ & $1.585 \times 10^{10}$ & $1.992 \times 10^{10}$ & $2.088 \times 10^{10}$ & $1.107 \times 10^{10}$ & $1.238 \times 10^{10}$ \\
\hline M73.13.2 & $4.471 \times 10^{10}$ & $4.732 \times 10^{10}$ & $5.763 \times 10^{10}$ & $5.212 \times 10^{10}$ & $1.247 \times 10^{10}$ & $7.613 \times 10^{10}$ & $3.325 \times 10^{10}$ & $3.541 \times 10^{10}$ \\
\hline M74.9.1 & $2.771 \times 10^{11}$ & $2.794 \times 10^{11}$ & $2.954 \times 10^{11}$ & $3.012 \times 10^{11}$ & $3.243 \times 10^{11}$ & $3.704 \times 10^{11}$ & $2.270 \times 10^{11}$ & $2.552 \times 10^{11}$ \\
\hline M75.9.2 & $6.529 \times 10^{11}$ & $6.561 \times 10^{11}$ & $6.813 \times 10^{11}$ & $7.000 \times 10^{11}$ & $7.222 \times 10^{11}$ & $8.316 \times 10^{11}$ & $5.503 \times 10^{11}$ & $6.154 \times 10^{11}$ \\
\hline M78.2.4 & $1.889 \times 10^{10}$ & $1.969 \times 10^{10}$ & $2.311 \times 10^{10}$ & $2.171 \times 10^{10}$ & $3.793 \times 10^{10}$ & $3.064 \times 10^{10}$ & $1.422 \times 10^{10}$ & $1.548 \times 10^{10}$ \\
\hline Minimum & $1.418 \times 10^{10}$ & $1.447 \times 10^{10}$ & $1.599 \times 10^{10}$ & $1.585 \times 10^{10}$ & $1.992 \times 10^{10}$ & $2.088 \times 10^{10}$ & $1.107 \times 10^{10}$ & $1.238 \times 10^{10}$ \\
\hline
\end{tabular}

After the execution of the correlation-based multicollinearity and coefficient tests with the removal

Table 7 Best model using 8SC 
of variables $\left(\mathrm{X}_{2}, \mathrm{X}_{3}, \mathrm{X}_{4}, \mathrm{X}_{35}, \mathrm{X}_{45}, \mathrm{X}_{234}\right.$, and $\left.\mathrm{X}_{235}\right)$, model equation of M72.2.5 is thus obtained as in (4) where $\hat{Y}$ is the forecasted biomass production volume of empy fruit bunches:-

$$
\text { M72.2.5: } \hat{Y}=\hat{\beta}_{0}+\hat{\beta}_{5} \mathrm{X}_{5}+\hat{\beta}_{23} \mathrm{X}_{23}+\hat{\beta}_{24} \mathrm{X}_{24}+\hat{\beta}_{25} \mathrm{X}_{25}+\hat{\beta}_{34} \mathrm{X}_{34}+
$$$$
\hat{\beta}_{245} \mathrm{X}_{245}+\hat{\beta}_{345} \mathrm{X}_{345}
$$

Table 8 shows the coefficient table of the best model M72.2.5 after the coefficient test has been carried out. In the elimination procedure of the coefficient test in Phase 2 as in Fig. 3, the most insignificant variable is removed one by one, and the insignificant variable is determined when the highest p-value is greater than $5 \%$ or with |tcal| greater than the critical value and nearest to zero ${ }^{14}$. The remaining factors have all the p-values less than 0.05 , thus indicating that they are all significant.

Table 9 shows the Pearson correlation matrix for

Table 8 Coefficient table for Model M72.2.5

\begin{tabular}{c|c|c|c|c}
\hline & Coefficients & $\begin{array}{c}\text { Standard } \\
\text { Error }\end{array}$ & t Stat & P-value \\
\hline Intercept & $3.158 \times 10^{7}$ & $1.061 \times 10^{6}$ & 29.76338 & $9.220 \times 10-17$ \\
\hline $\mathrm{X}_{5}$ & $-9.204 \times 10^{9}$ & $3.107 \times 10^{8}$ & -29.62371 & $1.002 \times 10^{-16}$ \\
\hline $\mathrm{X}_{23}$ & $1.671 \times 10^{-3}$ & $1.985 \times 10^{-5}$ & 84.17172 & $8.004 \times 10^{-25}$ \\
\hline $\mathrm{X}_{24}$ & $2.737 \times 10^{2}$ & $9.827 \times 10^{0}$ & 27.84922 & $2.978 \times 10^{-16}$ \\
\hline $\mathrm{X}_{25}$ & $1.290 \times 10^{3}$ & $1.289 \times 10^{2}$ & 10.01133 & $8.777 \times 10^{-9}$ \\
\hline $\mathrm{X}_{34}$ & $-1.648 \times 10^{5}$ & $4.646 \times 10^{3}$ & -35.48400 & $4.097 \times 10^{-18}$ \\
\hline $\mathrm{X}_{245}$ & $-4.895 \times 10^{4}$ & $5.214 \times 10^{3}$ & -9.38858 & $2.337 \times 10^{-8}$ \\
\hline $\mathrm{X}_{345}$ & $4.835 \times 10^{7}$ & $1.444 \times 10^{6}$ & 33.47994 & $1.149 \times 10^{-17}$ \\
\hline
\end{tabular}

the best model M72.2.5 after the multicollinearity and the coefficient tests have been carried out. The table shows the correlation between each significant determining factor $\left(\mathrm{X}_{5}, \mathrm{X}_{23}, \mathrm{X}_{24}, \mathrm{X}_{25}, \mathrm{X}_{34}, \mathrm{X}_{245}\right.$ and $\left.\mathrm{X}_{345}\right)$ with the production of oil palm fruits, $\mathrm{Y}$. The factor which is the most highly and positively correlated with the production of oil palm fruits is $\mathrm{X}_{23}$ and the factor which is the most weakly and negatively correlated with production of oil palm fruits is $\mathrm{X}_{34}$.

Referring to the coefficient table in Table 8 , by putting the values of the coefficients into the best model of M72.2.5 regression equation as in (4), equation (5) is thus obtained:

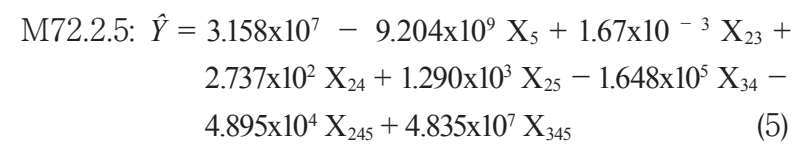

The Goodness-of-fit tests of Phase 4 can also be tested through the scatter and normality plots as supporting evidences. Fig. 6(a) shows the scatter plot for best model M72.2.5. From the scatter plot, almost all the standardized residuals are within the range of \pm 3 of standard deviations. Hence, the standardized residuals for the best model of Model I are said to be randomly distributed. In addition, the goodness of a regression model is also verified by the normality of the standardized residuals. The normality test on the standardized residuals based on Shapiro-Wilk statistics ( $\mathrm{df}=26$ ) gives a value of 0.956 with a significant p-value of 0.327 , hence, greater than 0.05 significance level.

Table 9 Pearson correlation matrix for Model M72.2.5

\begin{tabular}{c|c|c|c|c|c|c|c|c}
\hline & $\mathrm{Y}$ & $\mathrm{X}_{5}$ & $\mathrm{X}_{23}$ & $\mathrm{X}_{24}$ & $\mathrm{X}_{25}$ & $\mathrm{X}_{34}$ & $\mathrm{X}_{245}$ & $\mathrm{X}_{345}$ \\
\hline $\mathrm{Y}$ & 1.0000 & -0.9801 & 0.9853 & 0.9277 & 0.8968 & -0.2883 & 0.6067 & -0.7165 \\
\hline $\mathrm{X}_{5}$ & -0.9801 & 1.0000 & -0.9485 & -0.8729 & -0.8439 & 0.3851 & -0.4941 & 0.7805 \\
\hline $\mathrm{X}_{23}$ & 0.9853 & -0.9485 & 1.0000 & 0.9120 & 0.8581 & -0.1686 & 0.5987 & -0.6261 \\
\hline $\mathrm{X}_{24}$ & 0.9277 & -0.8729 & 0.9120 & 1.0000 & 0.9353 & -0.1002 & 0.8347 & -0.5571 \\
\hline $\mathrm{X}_{25}$ & 0.8968 & -0.8439 & 0.8581 & 0.9353 & 1.0000 & -0.2493 & 0.8333 & -0.6328 \\
\hline $\mathrm{X}_{34}$ & -0.2883 & 0.3851 & -0.1686 & -0.1002 & -0.2493 & 1.0000 & 0.1752 & 0.8659 \\
\hline $\mathrm{X}_{245}$ & 0.6067 & -0.4941 & 0.5987 & 0.8347 & 0.8333 & 0.1752 & 1.0000 & -0.1904 \\
\hline $\mathrm{X}_{345}$ & -0.7165 & 0.7805 & -0.6261 & -0.5571 & -0.6328 & 0.8659 & -0.1904 & 1.0000 \\
\hline
\end{tabular}
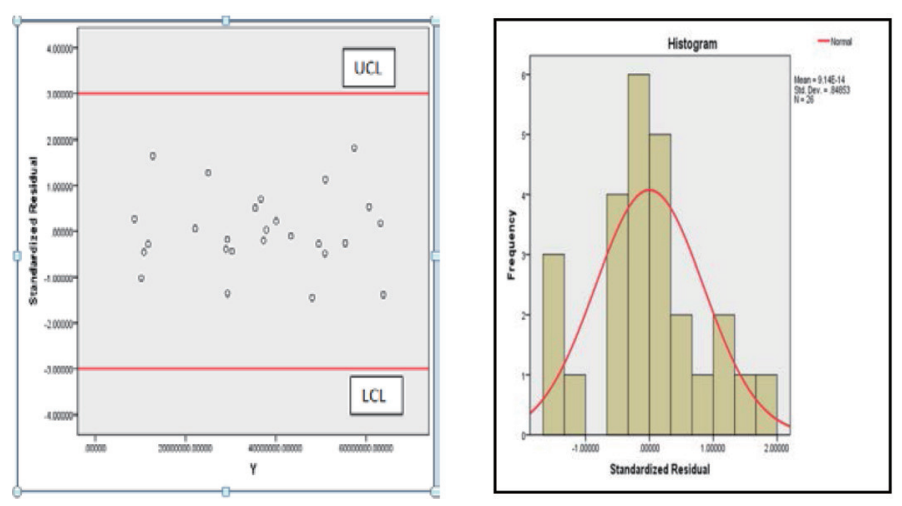

Fig. 6 The goodness-of-fit tests for M72.2.5 
Table 10 Reserved data for validation

\begin{tabular}{c|c|c|c|c|c}
\hline $\mathrm{Y}$ & $\mathrm{X} 1$ & $\mathrm{X} 2$ & $\mathrm{X} 3$ & $\mathrm{X} 4$ & $\mathrm{X} 5$ \\
\hline 87749835.0000 & 3947763.0000 & 3915924.0000 & 20.1800 & 2777.5000 & 500817.0000 \\
\hline 66766810.0000 & 4082124.0000 & 3477438.0000 & 19.2000 & 2236.5000 & 502229.0000 \\
\hline 64282738.0000 & 4202381.0000 & 3565321.0000 & 18.0300 & 2701.0000 & 446368.0000 \\
\hline 71384441.0000 & 4302283.0000 & 3625416.0000 & 19.6900 & 3219.0000 & 421465.0000 \\
\hline 69834479.0000 & 4385241.0000 & 3696902.0000 & 18.8900 & 2764.0000 & 435763.0000 \\
\hline
\end{tabular}

Table 11 Reserved data used for MAPE of Model II (model transformation method)

\begin{tabular}{|c|c|c|c|}
\hline $\begin{array}{l}\text { Actual Y } \\
\text { (At) }\end{array}$ & $\begin{array}{c}\text { Estimated Y } \\
\text { (Est) }\end{array}$ & $\begin{array}{c}\text { APE } \\
\text { (At-Est)/At }\end{array}$ & $\mathrm{APE} \times 100$ \\
\hline 87749835.0000 & 79633121.5502 & 0.0925 & 9.2498 \\
\hline 66766810.0000 & 66637226.4694 & 0.0019 & 0.1941 \\
\hline 64282738.0000 & 62918626.7757 & 0.0212 & 2.1220 \\
\hline 71384441.0000 & 71364957.3186 & 0.0003 & 0.0273 \\
\hline 69834479.0000 & 68796599.1205 & 0.0149 & 1.4862 \\
\hline \multirow{2}{*}{ (2) } & & Total & 13.0795 \\
\hline & & MAPE & 2.6159 \\
\hline
\end{tabular}

The standardized residuals are thus said to be normally distributed. The bell-shaped normality plot as shown in Fig. 6(b), depicts that model M72.2.5 is normally distributed. As mentioned earlier, regression modelling is carried out as shown by the model-building approaches to obtain Model I, where the best model is obtained and justified via the phases in model-building. Using the best model from Model I and suffice with a smaller data set of five, forecasting is then carried out to show the Model I best model's robustness with its low MAPE value, and this is then named as Model II. The following forecasting procedures are thus performed on the reserved data.

Table 10 shows the five reserved data which are the transfomed variables of Model I from Table 4. These data have been selected randomly for validation of the best model M72.2.5 obtained from Model I. By substituting the values into equation (5), the forecasted $\mathrm{Y}$ values can thus be obtained. Table 11 shows the actual Y and forecasted Y values of the reserved data.
Table 12 Coefficient table for biofuel volume M2.0.0

\begin{tabular}{c|c|c|c|c}
\hline & Coefficients & $\begin{array}{c}\text { Standard } \\
\text { Error }\end{array}$ & t Stat & P-value \\
\hline Intercept & $-1.863 \times 10^{3}$ & $2.136 \times 10^{4}$ & -0.08723 & 0.93598 \\
\hline$X_{2}$ & $3.411 \times 10^{2}$ & $5.014 \times 10$ & 6.80277 & 0.00650 \\
\hline
\end{tabular}

By substituting all the observations of actual $\mathrm{Y}$ and forecasted $\mathrm{Y}$ values into equation (5), the MAPE value is hence calculated. Table 11 shows that the MAPE value is calculated to be about $2.62 \%$. Since the MAPE value is less than $25 \%$, this is thus considered to be an acceptable excellent model that can be used for forecasting. This model then is used to estimate the biomass production volume for biomass fuel and biofuel.

For Model II, there is only one selected model which is M2.0.0. The forecasted liquid biofuel production volume model is shown below in (6) and with values of coefficients from Table 12 in equation (7):

$$
\begin{aligned}
& M 2.0 .0: \hat{Y}=\hat{B}_{0}+\hat{B}_{2} X_{2} \\
& M 2.0 .0=\hat{Y}=-1.863 \times 10^{3}+3.411 \times 10^{2} X_{2}
\end{aligned}
$$

The forecasted liquid biofuel production volume model is also subjected to the goodness-of-fit test of Phase 4 for its robustness for forecasting and prediction as shown in Fig. 7.

The scatter plot for Model M2.0.0 is used as supporting evidence to support that the model is randomly distributed. From the scatter plot in Fig. 7(a) below, almost all the standardized residuals are within the range of \pm 3 standard deviations. Hence, the standardized residuals for the biofuel production volume model M2.0.0 are said

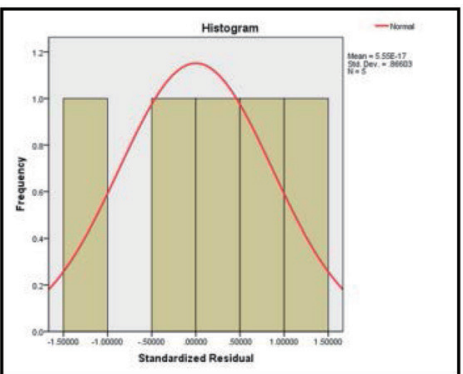

(b) Normality plot

(a) Scatter plot

Fig. 7 Goodness-of-fit tests for Model M2.0.0 
to be randomly distributed. The normality test on the standardized residuals based on the Shapiro-Wilk statistics $(\mathrm{df}=5)$ gives a value of 0.995 with a significant $\mathrm{p}$-value of 0.995 (Fig. 7(b)). Since it is greater than at 0.05 level, therefore, the standardized residuals are said to be normally distributed.

\section{Discussions}

From the forecasted model M72.2.5 in equation (5), it is thus found that the significant variables that have contributed to the production of oil palm fruits are one single independent variable, $\mathrm{X}_{5}$ and six interaction variables $\left(\mathrm{X}_{23}, \mathrm{X}_{24}, \mathrm{X}_{25}\right.$ and $\mathrm{X}_{34}$ - first order; $\mathrm{X}_{245}$ and $\mathrm{X}_{345}$ - second order). It is realized that these interaction variables have significant contribution to the production model, and they cannot occur as single independent variables. From equation (5), the forecasted biomass production model M72.2.5 can be described as that the total workers employed during the last pay period $\left(\mathrm{X}_{5}\right)$ is the only single main factor in the model that gives a negative contribution to the production of oil palm fruit bunches. This means that for every increase in tonnes in the biomass production, the number of workers employed should be reduced so as to attain optimal production. The increase in workers employed, in reality do not necessarily mean there will be an increase in biomass production from oil palm fruits bunches. In this study, this model equation thus implicates that the surplus of workers employed in large plantations have to be reduced for optimal production of biomass from harvested fruit bunches. In other words, for every single increase (or decrease) in the total number of workers employed during the last pay period will cause a decrease (or increase) in the production of oil palm fruit bunches for approximately $9.204 \times 10^{9}$ tonnes and vice versa. This factor also has a strong correlation (0.9801) with the production of oil palm fruits, meaning that in the Malaysian context, increase in fresh oil palm fruit bunches production with less workers can be achieved effectively with more R \& D activities in automotive inventions and innovative management planning and practices during planting, cropping, harvesting, and etc.

There are six interaction factors exist in the best model. They are the first order interaction factors namely, the harvested area that interacts with the oil palm yield per hectare $\left(\mathrm{X}_{23}\right)$ i.e. the harvested area $\left(\mathrm{X}_{2}\right)$ which interacts with the yield per hectare $\left(\mathrm{X}_{3}\right)$, the harvested area that interacts with the local delivery average price $\left(\mathrm{X}_{24}\right)$, i.e. the harvested area $\left(\mathrm{X}_{2}\right)$ which interacts with local delivery average price $\left(\mathrm{X}_{4}\right)$, and the harvested area that interacts with the total workers employed during last pay period $\left(\mathrm{X}_{25}\right)$, i.e. the harvested area $\left(\mathrm{X}_{2}\right)$ which interacts with the total workers employed during last pay period $\left(\mathrm{X}_{5}\right)$, all show positive contributions to the production of oil palm fruits, especially significantly by $\mathrm{X}_{24}$ and $\mathrm{X}_{25}$ respectively. This means that these first order interactions are positively related with the production of fresh oil palm fruits. However, the yield per hectare that interacts with the local delivery average price $\left(\mathrm{X}_{34}\right)$, i.e. the yield per hectare $\left(\mathrm{X}_{3}\right)$ which interacts with the local delivery average price $\left(\mathrm{X}_{4}\right)$, shows a negative contribution of $1.648 \times 10^{5}$ to every increase in the biomass production of oil palm fruits. It has a weak correlation (0.2883) with the production of oil palm fruits. The factor which is the most highly and positively correlated with the production of oil palm fruits is $\mathrm{X}_{23}$ while the factor which is the most weakly and negatively correlated with production of oil palm fruits is $\mathrm{X}_{34}$.

In addition, the second order interaction factor, the harvested area that interacts with the local delivery average price and with the total workers employed during last pay period $\left(\mathrm{X}_{245}\right)$ that is, harvested area $\left(\mathrm{X}_{2}\right)$ which interacts with local delivery average price $\left(\mathrm{X}_{4}\right)$ and the total workers employed during last pay period $\left(\mathrm{X}_{5}\right)$ shows a negative contribution and mediumly correlated (0.6067) to the production of oil palm fruit bunches. Lastly, another second order interaction i.e. the yield per hectare that interacts with the local delivery average price and with the total workers employed during last pay period $\left(\mathrm{X}_{345}\right)$ that is, yield per hectare $\left(\mathrm{X}_{3}\right)$ which interacts with the local delivery average price $\left(\mathrm{X}_{4}\right)$ and the total workers employed during last pay period $\left(\mathrm{X}_{5}\right)$ implies that there is a significant positive contribution of $4.835 \times 10^{7}$ with a medium correlation (0.7165) to the biomass production of oil palm fruits. Thus, it can be said that the collective contributions are determined by the regression coefficients of the significant factors in the model, namely by the yield and the harvested area of oil palm fruits. The best model equation obtained contains interaction factors whereby these variables individually will exhibit weak correlations, hence were removed during the model-building processes. However, the product of these variables involving first, and second order interactions exhibit strong correlations and positive contribution to the biomass production. This study thus implies the significant roles of interaction variables in the estimation and prediction of the dependent variable (i.e. the biomass production of fresh oil palm fruit bunches).

The value of $3.158 \times 10^{7}$ which is the intercept of the model, is just an arbitrary constant. This value implies the production of fresh oil palm fruit bunches in tonnes when all the other independent variables from the model are equal to zero. This is a mechanical interpretation of the intercept term ${ }^{24)}$. In regression analysis, however, 
such literal interpretation of the intercept term may be meaningless. The size of this arbitrary value is not relative and significant in the model. Paradoxically, while the value is generally meaningless, it is crucial to include the constant term in most of the regression models. It can thus guarantee that the residuals have a mean of zero, and additionally, it can also avoid the regression coefficients and predictions of the models to be biased. In this research, from the best model of Model I, the biomass production from fresh oil palm fruit bunches can thus be estimated.

The estimated biomass production in Model I in turn is used as an independent variable in Model II that can be further used to indicate the production volume of liquid biofuel (ie. biodiesel). Model M2.0.0 is shown to be the forecasted model for liquid biofuel production. It is found out that the main significant factor that contributes to the production volume of biodiesel is the export value of biodiesel itself. The export value of the biodiesel $\left(\mathrm{X}_{2}\right)$ gives a significant positive contribution of 341.1 to every single increase in the biofuel (biodiesel) production, and it has a strong correlation of 0.9691 with the biodiesel production volume. The value of $-1.863 \times 10^{3}$ also just an arbitrary constant, is the intercept of the model implies that the production volume of biodiesel in tonnes when all the independent variables from the model are equal to zero. Since it is impossible for the production volume to have a negative value, hence, the intercept term is meaningless.

The best model M72.2.5 for Model I has undergone the MAPE test for forecasting purposes in Model II. The positive coefficient of the export value of biodiesel in the model in equation (7) shows the positive contribution to the production volume of biodiesel with an MAPE value of approximately $2.62 \%$. Since the value is less than $25 \%$, model M72.2.5 is hence suitable for use in forecasting the production volume of biomass and biofuel.

\section{Conclusions}

This research is carried out to determine the significant factors that would contribute to the production of biomass fuel from fresh oil palm fruit bunches, and ultimately, can also be used to forecast the liquid biofuel production volume during the cogeneration processes ${ }^{1)}$. Overall, the best model obtained using the model transformation method implicates that the main factor that influences the production of biomass is the total workers employed during last pay period, followed by the common interaction factors, i.e. the yield and the harvested area of the oil palm fruits.

This research also manages to identify the factor that influences the liquid biofuel production volume. The best model indicates that the main factor influencing the biofuel production is the export value of liquid biofuel, specifically biodiesel. This means that the export value of biofuel would increase the production volume of biofuel when the price value of biofuel has attained an economic and competitive global market pricing.

This study also aims in introducing the modelling and forecasting procedures in multiple regression analysis involving model-building procedures and data reservation for model's robustness. This research has successfully shown that multiple regression technique with its modelbuilding procedures can be used to model and forecast the biomass and biofuel production to an acceptable good accuracy based on the low MAPE value. The MR technique has highlighted the removal of insignificant factors and the effect of interaction factors on the production and forecasting model. Further works can be done in looking at how efficient is biomass in producing heat or thermal energy from cogeneration processes, and the effectiveness of the technologically designed models in producing an optimal amount. This model is developed based on the oil palm plantations grown in the Malaysian context. Other works are suggested to be carried out on other oil palm producing countries where green technologies and energies have been proposed and implemented. Recent studies on fossil fuel reserves has indicated its decline and depletion ${ }^{25}$ 26) with the potential impacts on energy resources situation, important geo-political issues, impact on global climate and major global trends have to be addressed ${ }^{27}$. In other words, quantum efforts have to be made by environmentally concerned governments, green movements and nongovernmental organisations (NGOs), green technologies companies, and etc. in pressurising oil producing countries such as OPEC, to help and be involved in stabilising the price and regulating the policies regarding this sustainable green energy for future energy resources.

\section{References}

1) Muhammad Aziz; Oda, T;. Kashiwagi, T., J. Jpn. Inst. Energy, 94, 143-150 (2015)

2) Yusof, B., Global Oils and Fats Business Magazine, 5(3), 1-7 (2008)

3) Fadli, F. A. H. A.; Hayati, N. A. R.; Errie, A. A. R.; Bashir, A. S.A,; hana, N. A. H.; Jusoft, K., World Applied Sciences Journal, 12, 34-40 (2011)

4) Department of Statistics Malaysia (DOSM), available online at http://www.statistics.gov.my/main/main.php. (2011)

5) Malaysian Palm Oil Board (MPOB), available online at http://www.mpob.gov.my/. (2013) 
6) Vries, G., What is Mathematical Modeling. Department of Mathematical Sciences. University of Alberta. Canada. (2001); available at: http://www.math.ualberta. ca/ devries/erc2001/slides.pdf. (Retrieved: 13 October 2013)

7) Roxy, P.; Chris, O.; Jay, D., Introduction to Statistics and Data Analysis, 4th edition, Cengage Learning, United States (2011)

8) Zainodin, H. J.; Noraini Abdullah; Khuneswari, G., Science International, 2(3), 64-71 (2014)

9) Noraini Abdullah; Zainodin, H. J.; Amran Ahmed, Research Journal of Forestry, 6(1), 1-15 (2012)

10) Noraini Abdullah; Amran Ahmed; Zainodin, H. J., Journal of Science \& Technology (UTHM), 3(2), 29-42 (2011)

11) Noraini, Abdullah; Zainodin H. J., Science International, 2(2), 44-50 (2014)

12) Zainodin H. J.; Khuneswari G., Malaysian Journal of Mathematical Sciences, 3, 27-44 (2009)

13) Noraini Abdullah; Zainodin H. J., Department of Mathematical Sciences (UTM), MATEMATIKA, 29, 107-115 (2013)

14) Noraini Abdullah; Zainodin H. J.; Nigel Jonney J. J., Wseas Transaction on Mathematics, 7(7), 492-502 ((2008)

15) Zainodin H. J.; Noraini Abdullah; Yap S. J., Trends in Applied Sciences Research, 6(11), 1241-1255 (2011)

16) Akaike, H., IEEE Transactions Automatic Control AC, 19 , 716-723 (1974)

17) Rice, J., Annals of Statistics, 12, 1215-1230 (1984)

18) Akaike, H., Annals of the Institute of Statistical Mathematics, 21, 243-247 (1969)

19) Schwarz, G., Annals of Statistics, 6(2), 461-464 (1978)

20) Golub, G. H.; Heath, M.; Wahba, G., Technometrics, 21, 215-223 (1979)

21) Ramanathan, R., 2002, Introductory Econometrics with Applications. 5th edition. Texas: Harcourt College Publishers (2002)

22) Hannan, E. J.; Quinn, B., Journal of the Royal Statistical Society, 41, 190-195 (1979)

23) Shibata, R., Biometrika, 68(1), 45-54 (1981)

24) Gujarati, D. N.; Porter, D. C., Essentials of Econometrics, 5th edition, McGraw-Hill, New York (2009)

25) Shafiee, S.; Topal, E., Energy Policy, 37, 181-189 (2009)

26) Bharat Raj Singh; Onkar Singh, Fossil Fuel and the Environment, Dr. Shahriar Khan (Ed.), ISBN: 978953-51-0277-9, InTech, DOI: 10.5772/38655. Available from:http://www.intechopen.com/books/fossil-fuel-andthe-environment/global-trends-of-fossil-fuel-reservesand-climate-change-in-the-21st-century (2012)

27) Ecotricity, Our Green Energy, End of Fossil Fuels; available: http://www.ecotricity.co.uk/our-green-energy/ energy-independence/the-end-of- fossil-fuels.

\section{Appendix}

All possible 80 models in Model I

M1: $\mathrm{Y}=\beta_{0}+\beta_{1} \mathrm{X}_{1}+\mathrm{u}$

$\mathrm{M} 2: \mathrm{Y}=\beta_{0}+\beta_{2} \mathrm{X}_{2}+\mathrm{u}$

M3: $\mathrm{Y}=\beta_{0}+\beta_{3} \mathrm{X}_{3}+\mathrm{u}$

M4: $\mathrm{Y}=\beta_{0}+\beta_{4} \mathrm{X}_{4}+\mathrm{u}$

M5: $\mathrm{Y}=\beta_{0}+\beta_{5} \mathrm{X}_{5}+\mathrm{u}$

M6: $\mathrm{Y}=\beta_{0}+\beta_{1} \mathrm{X}_{1}+\beta_{2} \mathrm{X}_{2}+\mathrm{u}$

M7: $\mathrm{Y}=\beta_{0}+\beta_{1} \mathrm{X}_{1}+\beta_{3} \mathrm{X}_{3}+\mathrm{u}$

M8: $\mathrm{Y}=\beta_{0}+\beta_{1} \mathrm{X}_{1}+\beta_{4} \mathrm{X}_{4}+\mathrm{u}$

M9: $\mathrm{Y}=\beta_{0}+\beta_{1} \mathrm{X}_{1}+\beta_{5} \mathrm{X}_{5}+\mathrm{u}$

M10: $\mathrm{Y}=\beta_{0}+\beta_{2} \mathrm{X}_{2}+\beta_{3} \mathrm{X}_{3}+\mathrm{u}$

M11: $\mathrm{Y}=\beta_{0}+\beta_{2} \mathrm{X}_{2}+\beta_{4} \mathrm{X}_{4}+\mathrm{u}$

M12: $\mathrm{Y}=\beta_{0}+\beta_{2} \mathrm{X}_{2}+\beta_{5} \mathrm{X}_{5}+\mathrm{u}$

M13: $\mathrm{Y}=\beta_{0}+\beta_{3} \mathrm{X}_{3}+\beta_{4} \mathrm{X}_{4}+\mathrm{u}$

M14: $\mathrm{Y}=\beta_{0}+\beta_{3} \mathrm{X}_{3}+\beta_{5} \mathrm{X}_{5}+\mathrm{u}$

M15: $\mathrm{Y}=\beta_{0}+\beta_{4} \mathrm{X}_{4}+\beta_{5} \mathrm{X}_{5}+\mathrm{u}$

M16: $\mathrm{Y}=\beta_{0}+\beta_{1} \mathrm{X}_{1}+\beta_{2} \mathrm{X}_{2}+\beta_{3} \mathrm{X}_{3}+\mathrm{u}$

M17: $\mathrm{Y}=\beta_{0}+\beta_{1} \mathrm{X}_{1}+\beta_{2} \mathrm{X}_{2}+\beta_{4} \mathrm{X}_{4}+\mathrm{u}$

M18: $\mathrm{Y}=\beta_{0}+\beta_{1} \mathrm{X}_{1}+\beta_{2} \mathrm{X}_{2}+\beta_{5} \mathrm{X}_{5}+\mathrm{u}$

M19: $\mathrm{Y}=\beta_{0}+\beta_{1} \mathrm{X}_{1}+\beta_{3} \mathrm{X}_{3}+\beta_{4} \mathrm{X}_{4}+\mathrm{u}$

M20: $\mathrm{Y}=\beta_{0}+\beta_{1} \mathrm{X}_{1}+\beta_{3} \mathrm{X}_{3}+\beta_{5} \mathrm{X}_{5}+\mathrm{u}$

M21: $\mathrm{Y}=\beta_{0}+\beta_{1} \mathrm{X}_{1}+\beta_{4} \mathrm{X}_{4}+\beta_{5} \mathrm{X}_{5}+\mathrm{u}$

$\mathrm{M} 22: \mathrm{Y}=\beta_{0}+\beta_{2} \mathrm{X}_{2}+\beta_{3} \mathrm{X}_{3}+\beta_{4} \mathrm{X}_{4}+\mathrm{u}$

M23: $\mathrm{Y}=\beta_{0}+\beta_{2} \mathrm{X}_{2}+\beta_{3} \mathrm{X}_{3}+\beta_{5} \mathrm{X}_{5}+\mathrm{u}$

M24: $\mathrm{Y}=\beta_{0}+\beta_{2} \mathrm{X}_{2}+\beta_{4} \mathrm{X}_{4}+\beta_{5} \mathrm{X}_{5}+\mathrm{u}$

M25: $\mathrm{Y}=\beta_{0}+\beta_{3} \mathrm{X}_{3}+\beta_{4} \mathrm{X}_{4}+\beta_{5} \mathrm{X}_{5}+\mathrm{u}$

M26: $\mathrm{Y}=\beta_{0}+\beta_{1} \mathrm{X}_{1}+\beta_{2} \mathrm{X}_{2}+\beta_{3} \mathrm{X}_{3}+\beta_{4} \mathrm{X}_{4}+\mathrm{u}$

$\mathrm{M} 27: \mathrm{Y}=\beta_{0}+\beta_{1} \mathrm{X}_{1}+\beta_{2} \mathrm{X}_{2}+\beta_{3} \mathrm{X}_{3}+\beta_{5} \mathrm{X}_{5}+\mathrm{u}$

M28: $\mathrm{Y}=\beta_{0}+\beta_{1} \mathrm{X}_{1}+\beta_{2} \mathrm{X}_{2}+\beta_{4} \mathrm{X}_{4}+\beta_{5} \mathrm{X}_{5}+\mathrm{u}$

M29: $\mathrm{Y}=\beta_{0}+\beta_{1} \mathrm{X}_{1}+\beta_{3} \mathrm{X}_{3}+\beta_{4} \mathrm{X}_{4}+\beta_{5} \mathrm{X}_{5}+\mathrm{u}$

M30: $\mathrm{Y}=\beta_{0}+\beta_{2} \mathrm{X}_{2}+\beta_{3} \mathrm{X}_{3}+\beta_{4} \mathrm{X}_{4}+\beta_{5} \mathrm{X}_{5}+\mathrm{u}$

M31: $\mathrm{Y}=\beta_{0}+\beta_{1} \mathrm{X}_{1}+\beta_{2} \mathrm{X}_{2}+\beta_{3} \mathrm{X}_{3}+\beta_{4} \mathrm{X}_{4}+\beta_{5} \mathrm{X}_{5}+\mathrm{u}$

M32: $\mathrm{Y}=\beta_{0}+\beta_{1} \mathrm{X}_{1}+\beta_{2} \mathrm{X}_{2}+\beta_{12} \mathrm{X}_{12}+\mathrm{u}$

M33: $\mathrm{Y}=\beta_{0}+\beta_{1} \mathrm{X}_{1}+\beta_{3} \mathrm{X}_{3}+\beta_{13} \mathrm{X}_{13}+\mathrm{u}$

M34: $\mathrm{Y}=\beta_{0}+\beta_{1} \mathrm{X}_{1}+\beta_{4} \mathrm{X}_{4}+\beta_{14} \mathrm{X}_{14}+\mathrm{u}$

M35: $\mathrm{Y}=\beta_{0}+\beta_{1} \mathrm{X}_{1}+\beta_{5} \mathrm{X}_{5}+\beta_{15} \mathrm{X}_{15}+\mathrm{u}$

M36: $\mathrm{Y}=\beta_{0}+\beta_{2} \mathrm{X}_{2}+\beta_{3} \mathrm{X}_{3}+\beta_{23} \mathrm{X}_{23}+\mathrm{u}$

M37: $\mathrm{Y}=\beta_{0}+\beta_{2} \mathrm{X}_{2}+\beta_{4} \mathrm{X}_{4}+\beta_{24} \mathrm{X}_{24}+\mathrm{u}$

M38: $\mathrm{Y}=\beta_{0}+\beta_{2} \mathrm{X}_{2}+\beta_{5} \mathrm{X}_{5}+\beta_{25} \mathrm{X}_{25}+\mathrm{u}$

M39: $\mathrm{Y}=\beta_{0}+\beta_{3} \mathrm{X}_{3}+\beta_{4} \mathrm{X}_{4}+\beta_{34} \mathrm{X}_{34}+\mathrm{u}$

M40: $\mathrm{Y}=\beta_{0}+\beta_{3} \mathrm{X}_{3}+\beta_{5} \mathrm{X}_{5}+\beta_{35} \mathrm{X}_{35}+\mathrm{u}$

M41: $\mathrm{Y}=\beta_{0}+\beta_{4} \mathrm{X}_{4}+\beta_{5} \mathrm{X}_{5}+\beta_{45} \mathrm{X}_{45}+\mathrm{u}$

$\mathrm{M} 42: \mathrm{Y}=\beta_{0}+\beta_{1} \mathrm{X}_{1}+\beta_{2} \mathrm{X}_{2}+\beta_{3} \mathrm{X}_{3}+\beta_{12} \mathrm{X}_{12}+\beta_{13} \mathrm{X}_{13}+\beta_{23} \mathrm{X}_{23}+\mathrm{u}$

M43: $\mathrm{Y}=\beta_{0}+\beta_{1} \mathrm{X}_{1}+\beta_{2} \mathrm{X}_{2}+\beta_{4} \mathrm{X}_{4}+\beta_{12} \mathrm{X}_{12}+\beta_{14} \mathrm{X}_{14}+\beta_{24} \mathrm{X}_{24}+\mathrm{u}$

M44: $\mathrm{Y}=\beta_{0}+\beta_{1} \mathrm{X}_{1}+\beta_{2} \mathrm{X}_{2}+\beta_{5} \mathrm{X}_{5}+\beta_{12} \mathrm{X}_{12}+\beta_{15} \mathrm{X}_{15}+\beta_{25} \mathrm{X}_{25}+\mathrm{u}$

M45: $\mathrm{Y}=\beta_{0}+\beta_{1} \mathrm{X}_{1}+\beta_{3} \mathrm{X}_{3}+\beta_{4} \mathrm{X}_{4}+\beta_{13} \mathrm{X}_{13}+\beta_{14} \mathrm{X}_{14}+\beta_{34} \mathrm{X}_{34}+\mathrm{u}$ 
M46: $\mathrm{Y}=\beta_{0}+\beta_{1} \mathrm{X}_{1}+\beta_{3} \mathrm{X}_{3}+\beta_{5} \mathrm{X}_{5}+\beta_{13} \mathrm{X}_{13}+\beta_{15} \mathrm{X}_{15}+\beta_{35} \mathrm{X}_{35}+\mathrm{u}$ $\mathrm{M} 47: \mathrm{Y}=\beta_{0}+\beta_{1} \mathrm{X}_{1}+\beta_{4} \mathrm{X}_{4}+\beta_{5} \mathrm{X}_{5}+\beta_{14} \mathrm{X}_{14}+\beta_{15} \mathrm{X}_{15}+\beta_{45} \mathrm{X}_{45}+\mathrm{u}$ M48: $\mathrm{Y}=\beta_{0}+\beta_{2} \mathrm{X}_{2}+\beta_{3} \mathrm{X}_{3}+\beta_{4} \mathrm{X}_{4}+\beta_{23} \mathrm{X}_{23}+\beta_{24} \mathrm{X}_{24}+\beta_{34} \mathrm{X}_{34}+\mathrm{u}$ M49: $\mathrm{Y}=\beta_{0}+\beta_{2} \mathrm{X}_{2}+\beta_{3} \mathrm{X}_{3}+\beta_{5} \mathrm{X}_{5}+\beta_{23} \mathrm{X}_{23}+\beta_{25} \mathrm{X}_{25}+\beta_{35} \mathrm{X}_{35}+\mathrm{u}$ M50: $\mathrm{Y}=\beta_{0}+\beta_{2} \mathrm{X}_{2}+\beta_{4} \mathrm{X}_{4}+\beta_{5} \mathrm{X}_{5}+\beta_{24} \mathrm{X}_{24}+\beta_{25} \mathrm{X}_{25}+\beta_{45} \mathrm{X}_{45}+\mathrm{u}$ M51: $\mathrm{Y}=\beta_{0}+\beta_{3} \mathrm{X}_{3}+\beta_{4} \mathrm{X}_{4}+\beta_{5} \mathrm{X}_{5}+\beta_{34} \mathrm{X}_{34}+\beta_{35} \mathrm{X}_{35}+\beta_{45} \mathrm{X}_{45}+\mathrm{u}$ M52: $\mathrm{Y}=\beta_{0}+\beta_{1} \mathrm{X}_{1}+\beta_{2} \mathrm{X}_{2}+\beta_{3} \mathrm{X}_{3}+\beta_{4} \mathrm{X}_{4}+\beta_{12} \mathrm{X}_{12}+\beta_{13} \mathrm{X}_{13}+\beta_{14} \mathrm{X}_{14}+\beta_{23}$ $\mathrm{X}_{23}+\beta_{24} \mathrm{X}_{24}+\beta_{25} \mathrm{X}_{25}+\beta_{34} \mathrm{X}_{34}+\mathrm{u}$

$\mathrm{M} 53: \mathrm{Y}=\beta_{0}+\beta_{1} \mathrm{X}_{1}+\beta_{2} \mathrm{X}_{2}+\beta_{3} \mathrm{X}_{3}+\beta_{5} \mathrm{X}_{5}+\beta_{12} \mathrm{X}_{12}+\beta_{13} \mathrm{X}_{13}+\beta_{15} \mathrm{X}_{15}+\beta_{23}$ $\mathrm{X}_{23}+\beta_{25} \mathrm{X}_{25}+\beta_{45} \mathrm{X}_{45}+\mathrm{u}$

M54: $\mathrm{Y}=\beta_{0}+\beta_{1} \mathrm{X}_{1}+\beta_{2} \mathrm{X}_{2}+\beta_{4} \mathrm{X}_{4}+\beta_{5} \mathrm{X}_{5}+\beta_{12} \mathrm{X}_{12}+\beta_{14} \mathrm{X}_{14}+\beta_{15} \mathrm{X}_{15}+\beta_{24}$ $\mathrm{X}_{24}+\beta_{25} \mathrm{X}_{25}+\beta_{45} \mathrm{X}_{45}+\mathrm{u}$

M55: $\mathrm{Y}=\beta_{0}+\beta_{1} \mathrm{X}_{1}+\beta_{3} \mathrm{X}_{3}+\beta_{4} \mathrm{X}_{4}+\beta_{5} \mathrm{X}_{5}+\beta_{13} \mathrm{X}_{13}+\beta_{14} \mathrm{X}_{14}+\beta_{15} \mathrm{X}_{15}+\beta_{34}$ $\mathrm{X}_{34}+\beta_{35} \mathrm{X}_{35}+\beta_{45} \mathrm{X}_{45}+\mathrm{u}$

M56: $\mathrm{Y}=\beta_{0}+\beta_{2} \mathrm{X}_{2}+\beta_{3} \mathrm{X}_{3}+\beta_{4} \mathrm{X}_{4}+\beta_{5} \mathrm{X}_{5}+\beta_{23} \mathrm{X}_{23}+\beta_{24} \mathrm{X}_{24}+\beta_{25} \mathrm{X}_{25}+\beta_{34}$ $\mathrm{X}_{34}+\beta_{35} \mathrm{X}_{35}+\beta_{45} \mathrm{X}_{45}+\mathrm{u}$

M57: $\mathrm{Y}=\beta_{0}+\beta_{1} \mathrm{X}_{1}+\beta_{2} \mathrm{X}_{2}+\beta_{3} \mathrm{X}_{3}+\beta_{4} \mathrm{X}_{4}+\beta_{5} \mathrm{X}_{5}+\beta_{12} \mathrm{X}_{12}+\beta_{13} \mathrm{X}_{13}+\beta_{14}$ $\mathrm{X}_{14}+\beta_{15} \mathrm{X}_{15}+\beta_{23} \mathrm{X}_{23}+\beta_{24} \mathrm{X}_{24}+\beta_{25} \mathrm{X}_{25}+\beta_{34} \mathrm{X}_{34}+\beta_{35} \mathrm{X}_{35}+\beta_{45} \mathrm{X}_{45}+\mathrm{u}$

M58: $\mathrm{Y}=\beta_{0}+\beta_{1} \mathrm{X}_{1}+\beta_{2} \mathrm{X}_{2}+\beta_{3} \mathrm{X}_{3}+\beta_{12} \mathrm{X}_{12}+\beta_{13} \mathrm{X}_{13}+\beta_{23} \mathrm{X}_{23}+\beta_{123} \mathrm{X}_{123}$ $+\mathrm{u}$

M59: $\mathrm{Y}=\beta_{0}+\beta_{1} \mathrm{X}_{1}+\beta_{2} \mathrm{X}_{2}+\beta_{4} \mathrm{X}_{4}+\beta_{12} \mathrm{X}_{12}+\beta_{14} \mathrm{X}_{14}+\beta_{24} \mathrm{X}_{24}+\beta_{124} \mathrm{X}_{124}+\mathrm{u}$ M60: $\mathrm{Y}=\beta_{0}+\beta_{1} \mathrm{X}_{1}+\beta_{2} \mathrm{X}_{2}+\beta_{5} \mathrm{X}_{5}+\beta_{12} \mathrm{X}_{12}+\beta_{15} \mathrm{X}_{15}+\beta_{25} \mathrm{X}_{25}+\beta_{125} \mathrm{X}_{125}$ $+\mathrm{u}$

M61: $\mathrm{Y}=\beta_{0}+\beta_{1} \mathrm{X}_{1}+\beta_{3} \mathrm{X}_{3}+\beta_{4} \mathrm{X}_{4}+\beta_{13} \mathrm{X}_{13}+\beta_{14} \mathrm{X}_{14}+\beta_{34} \mathrm{X}_{34}+\beta_{134} \mathrm{X}_{134}+\mathrm{u}$ $\mathrm{M} 62: \mathrm{Y}=\beta_{0}+\beta_{1} \mathrm{X}_{1}+\beta_{3} \mathrm{X}_{3}+\beta_{5} \mathrm{X}_{5}+\beta_{13} \mathrm{X}_{13}+\beta_{15} \mathrm{X}_{15}+\beta_{35} \mathrm{X}_{35}+\beta_{135} \mathrm{X}_{135}+\mathrm{u}$ M63: $\mathrm{Y}=\beta_{0}+\beta_{1} \mathrm{X}_{1}+\beta_{4} \mathrm{X}_{4}+\beta_{5} \mathrm{X}_{5}+\beta_{14} \mathrm{X}_{14}+\beta_{15} \mathrm{X}_{15}+\beta_{45} \mathrm{X}_{45}+\beta_{145} \mathrm{X}_{145}+\mathrm{u}$ M64: $\mathrm{Y}=\beta_{0}+\beta_{2} \mathrm{X}_{2}+\beta_{3} \mathrm{X}_{3}+\beta_{4} \mathrm{X}_{4}+\beta_{23} \mathrm{X}_{23}+\beta_{24} \mathrm{X}_{24}+\beta_{34} \mathrm{X}_{34}+\beta_{234} \mathrm{X}_{234}$ $+\mathrm{u}$

M65: $\mathrm{Y}=\beta_{0}+\beta_{2} \mathrm{X}_{2}+\beta_{3} \mathrm{X}_{3}+\beta_{5} \mathrm{X}_{5}+\beta_{23} \mathrm{X}_{23}+\beta_{25} \mathrm{X}_{25}+\beta_{35} \mathrm{X}_{35}+\beta_{235} \mathrm{X}_{235}$ $+\mathrm{u}$

M66: $\mathrm{Y}=\beta_{0}+\beta_{2} \mathrm{X}_{2}+\beta_{4} \mathrm{X}_{4}+\beta_{5} \mathrm{X}_{5}+\beta_{24} \mathrm{X}_{24}+\beta_{25} \mathrm{X}_{25}+\beta_{45} \mathrm{X}_{45}+\beta_{245} \mathrm{X}_{245}$ $+\mathrm{u}$

M67: $\mathrm{Y}=\beta_{0}+\beta_{3} \mathrm{X}_{3}+\beta_{4} \mathrm{X}_{4}+\beta_{5} \mathrm{X}_{5}+\beta_{34} \mathrm{X}_{34}+\beta_{35} \mathrm{X}_{35}+\beta_{45} \mathrm{X}_{45}+\beta_{345} \mathrm{X}_{345}$ $+\mathrm{u}$

M68: $\mathrm{Y}=\beta_{0}+\beta_{1} \mathrm{X}_{1}+\beta_{2} \mathrm{X}_{2}+\beta_{3} \mathrm{X}_{3}+\beta_{4} \mathrm{X}_{4}+\beta_{12} \mathrm{X}_{12}+\beta_{13} \mathrm{X}_{13}+\beta_{14} \mathrm{X}_{14}+\beta_{23}$ $\mathrm{X}_{23}+\beta_{24} \mathrm{X}_{24}+\beta_{34} \mathrm{X}_{34}+\beta_{123} \mathrm{X}_{123}+\beta_{124} \mathrm{X}_{124}+\beta_{134} \mathrm{X}_{134}+\beta_{234} \mathrm{X}_{234}+\mathrm{u}$
M69: $\mathrm{Y}=\beta_{0}+\beta_{1} \mathrm{X}_{1}+\beta_{2} \mathrm{X}_{2}+\beta_{3} \mathrm{X}_{3}+\beta_{5} \mathrm{X}_{5}+\beta_{12} \mathrm{X}_{12}+\beta_{13} \mathrm{X}_{13}+\beta_{15} \mathrm{X}_{15}+\beta_{23}$ $\mathrm{X}_{23}+\beta_{25} \mathrm{X}_{25}+\beta_{35} \mathrm{X}_{35}+\beta_{123} \mathrm{X}_{123}+\beta_{125} \mathrm{X}_{125}+\beta_{135} \mathrm{X}_{135}+\beta_{235} \mathrm{X}_{235}+\mathrm{u}$ M70: $\mathrm{Y}=\beta_{0}+\beta_{1} \mathrm{X}_{1}+\beta_{2} \mathrm{X}_{2}+\beta_{4} \mathrm{X}_{4}+\beta_{5} \mathrm{X}_{5}+\beta_{12} \mathrm{X}_{12}+\beta_{14} \mathrm{X}_{14}+\beta_{15} \mathrm{X}_{15}+\beta_{24}$ $\mathrm{X}_{24}+\beta_{25} \mathrm{X}_{25}+\beta_{45} \mathrm{X}_{45}+\beta_{124} \mathrm{X}_{124}+\beta_{125} \mathrm{X}_{125}+\beta_{145} \mathrm{X}_{145}+\beta_{245} \mathrm{X}_{245}+\mathrm{u}$ $\mathrm{M} 71: \mathrm{Y}=\beta_{0}+\beta_{1} \mathrm{X}_{1}+\beta_{3} \mathrm{X}_{3}+\beta_{4} \mathrm{X}_{4}+\beta_{5} \mathrm{X}_{5}+\beta_{13} \mathrm{X}_{13}+\beta_{14} \mathrm{X}_{14}+\beta_{15} \mathrm{X}_{15}+\beta_{34}$ $\mathrm{X}_{34}+\beta_{35} \mathrm{X}_{35}+\beta_{45} \mathrm{X}_{45}+\beta_{134} \mathrm{X}_{134}+\beta_{135} \mathrm{X}_{135}+\beta_{145} \mathrm{X}_{145}+\beta_{345} \mathrm{X}_{345}+\mathrm{u}$ M72: $\mathrm{Y}=\beta_{0}+\beta_{2} \mathrm{X}_{2}+\beta_{3} \mathrm{X}_{3}+\beta_{4} \mathrm{X}_{4}+\beta_{5} \mathrm{X}_{5}+\beta_{23} \mathrm{X}_{23}+\beta_{24} \mathrm{X}_{24}+\beta_{25} \mathrm{X}_{25}+$ $\beta_{34} \mathrm{X}_{34}+\beta_{35} \mathrm{X}_{35}+\beta_{45} \mathrm{X}_{45}+\beta_{234} \mathrm{X}_{234}+\beta_{235} \mathrm{X}_{235}+\beta_{245} \mathrm{X}_{245}+\beta_{345} \mathrm{X}_{345}+\mathrm{u}$ M73: $\mathrm{Y}=\beta_{0}+\beta_{1} \mathrm{X}_{1}+\beta_{2} \mathrm{X}_{2}+\beta_{3} \mathrm{X}_{3}+\beta_{4} \mathrm{X}_{4}+\beta_{5} \mathrm{X}_{5}+\beta_{12} \mathrm{X}_{12}+\beta_{13} \mathrm{X}_{13}+\beta_{14}$ $\mathrm{X}_{14}+\beta_{15} \mathrm{X}_{15}+\beta_{23} \mathrm{X}_{23}+\beta_{24} \mathrm{X}_{24}+\beta_{25} \mathrm{X}_{25}+\beta_{34} \mathrm{X}_{34}+\beta_{35} \mathrm{X}_{35}+\beta_{45} \mathrm{X}_{45}+\beta_{234} \mathrm{X}_{234}$ $+\beta_{235} \mathrm{X}_{235}+\beta_{245} \mathrm{X}_{245}+\beta_{345} \mathrm{X}_{345}+\mathrm{u}$

M74: $\mathrm{Y}=\beta_{0}+\beta_{1} \mathrm{X}_{1}+\beta_{2} \mathrm{X}_{2}+\beta_{3} \mathrm{X}_{3}+\beta_{4} \mathrm{X}_{4}+\beta_{12} \mathrm{X}_{12}+\beta_{13} \mathrm{X}_{13}+\beta_{14} \mathrm{X}_{14}+\beta_{23}$ $\mathrm{X}_{23}+\beta_{24} \mathrm{X}_{24}+\beta_{34} \mathrm{X}_{34}+\beta_{123} \mathrm{X}_{123}+\beta_{124} \mathrm{X}_{124}+\beta_{134} \mathrm{X}_{134}+\beta_{234} \mathrm{X}_{234}+\beta_{1234} \mathrm{X}_{1234}$ $+\mathrm{u}$

M75: $\mathrm{Y}=\beta_{0}+\beta_{1} \mathrm{X}_{1}+\beta_{2} \mathrm{X}_{2}+\beta_{3} \mathrm{X}_{3}+\beta_{5} \mathrm{X}_{5}+\beta_{12} \mathrm{X}_{12}+\beta_{13} \mathrm{X}_{13}+\beta_{15} \mathrm{X}_{15}+\beta_{23}$ $\mathrm{X}_{23}+\beta_{25} \mathrm{X}_{25}+\beta_{35} \mathrm{X}_{35}+\beta_{123} \mathrm{X}_{123}+\beta_{125} \mathrm{X}_{125}+\beta_{135} \mathrm{X}_{135}+\beta_{235} \mathrm{X}_{235}+\beta_{1235} \mathrm{X}_{1235}$ $+\mathrm{u}$

M76: $\mathrm{Y}=\beta_{0}+\beta_{1} \mathrm{X}_{1}+\beta_{2} \mathrm{X}_{2}+\beta_{4} \mathrm{X}_{4}+\beta_{5} \mathrm{X}_{5}+\beta_{12} \mathrm{X}_{12}+\beta_{14} \mathrm{X}_{14}+\beta_{15} \mathrm{X}_{15}+\beta_{24}$ $\mathrm{X}_{24}+\beta_{25} \mathrm{X}_{25}+\beta_{45} \mathrm{X}_{45}+\beta_{124} \mathrm{X}_{124}+\beta_{125} \mathrm{X}_{125}+\beta_{145} \mathrm{X}_{145}+\beta_{245} \mathrm{X}_{245}+\beta_{1245} \mathrm{X}_{1245}$ $+\mathrm{u}$

M77: $\mathrm{Y}=\beta_{0}+\beta_{1} \mathrm{X}_{1}+\beta_{3} \mathrm{X}_{3}+\beta_{4} \mathrm{X}_{4}+\beta_{5} \mathrm{X}_{5}+\beta_{13} \mathrm{X}_{13}+\beta_{14} \mathrm{X}_{14}+\beta_{15} \mathrm{X}_{15}+\beta_{34}$ $\mathrm{X}_{34}+\beta_{35} \mathrm{X}_{35}+\beta_{45} \mathrm{X}_{45}+\beta_{134} \mathrm{X}_{134}+\beta_{135} \mathrm{X}_{135}+\beta_{145} \mathrm{X}_{145}+\beta_{345} \mathrm{X}_{345}+\beta_{1345} \mathrm{X}_{1345}$ $+\mathrm{u}$

M78: $\mathrm{Y}_{1}=\beta_{0}+\beta_{2} \mathrm{X}_{2}+\beta_{3} \mathrm{X}_{3}+\beta_{4} \mathrm{X}_{4}+\beta_{5} \mathrm{X}_{5}+\beta_{23} \mathrm{X}_{23}+\beta_{24} \mathrm{X}_{24}+\beta_{25} \mathrm{X}_{25}+$ $\beta_{34} \mathrm{X}_{34}+\beta_{35} \mathrm{X}_{35}+\beta_{45} \mathrm{X}_{45}+\beta_{234} \mathrm{X}_{234}+\beta_{235} \mathrm{X}_{235}+\beta_{245} \mathrm{X}_{245}+\beta_{345} \mathrm{X}_{345}+\beta_{2345}$ $\mathrm{X}_{2345}+\mathrm{u}$

M79: $\mathrm{Y}_{1}=\beta_{0}+\beta_{1} \mathrm{X}_{1}+\beta_{2} \mathrm{X}_{2}+\beta_{3} \mathrm{X}_{3}+\beta_{4} \mathrm{X}_{4}+\beta_{5} \mathrm{X}_{5}+\beta_{12} \mathrm{X}_{12}+\beta_{13} \mathrm{X}_{13}+\beta_{14}$ $\mathrm{X}_{14}+\beta_{15} \mathrm{X}_{15}+\beta_{23} \mathrm{X}_{23}+\beta_{24} \mathrm{X}_{24}+\beta_{25} \mathrm{X}_{25}+\beta_{34} \mathrm{X}_{34}+\beta_{35} \mathrm{X}_{35}+\beta_{45} \mathrm{X}_{45}+\beta_{124} \mathrm{X}_{12}$ ${ }_{4}+\beta_{125} \mathrm{X}_{125}+\beta_{134} \mathrm{X}_{134}+\beta_{135} \mathrm{X}_{135}+\beta_{145} \mathrm{X}_{145}+\beta_{234} \mathrm{X}_{234}+\beta_{235} \mathrm{X}_{235}+\beta_{245} \mathrm{X}_{245}+$ $\beta_{345} \mathrm{X}_{345}+\beta_{1234} \mathrm{X}_{1234}+\beta_{1235} \mathrm{X}_{1235}+\beta_{1245} \mathrm{X}_{1245}+\beta_{1345} \mathrm{X}_{1345}+\beta_{2345} \mathrm{X}_{2345}+\mathrm{u}$ M80: $\mathrm{Y}_{1}=\beta_{0}+\beta_{1} \mathrm{X}_{1}+\beta_{2} \mathrm{X}_{2}+\beta_{3} \mathrm{X}_{3}+\beta_{4} \mathrm{X}_{4}+\beta_{5} \mathrm{X}_{5}+\beta_{12} \mathrm{X}_{12}+\beta_{13} \mathrm{X}_{13}+\beta_{14}$ $\mathrm{X}_{14}+\beta_{15} \mathrm{X}_{15}+\beta_{23} \mathrm{X}_{23}+\beta_{24} \mathrm{X}_{24}+\beta_{25} \mathrm{X}_{25}+\beta_{34} \mathrm{X}_{34}+\beta_{35} \mathrm{X}_{35}+\beta_{45} \mathrm{X}_{45}+\beta_{123} \mathrm{X}_{12}$ ${ }_{3}+\beta_{124} \mathrm{X}_{124}+\beta_{125} \mathrm{X}_{125}+\beta_{134} \mathrm{X}_{134}+\beta_{135} \mathrm{X}_{135}+\beta_{145} \mathrm{X}_{145}+\beta_{234} \mathrm{X}_{234}+\beta_{235} \mathrm{X}_{235}+$ $\beta_{245} \mathrm{X}_{245}+\beta_{345} \mathrm{X}_{345}+\beta_{1234} \mathrm{X}_{1234}+\beta_{1235} \mathrm{X}_{1235}+\beta_{1245} \mathrm{X}_{1245}+\beta_{1345} \mathrm{X}_{1345}+\beta_{2345}$ $\mathrm{X}_{2345}+\beta_{12345} \mathrm{X}_{12345}+\mathrm{u}$ 